\title{
Application and Testing of the Extended-Kalman-Filtering Technique for Determining the Planetary Boundary-Layer Height over Athens, Greece
}

\author{
Panagiotis Kokkalis' Dimitrios Alexiou ${ }^{2}$ • Alexandros Papayannis ${ }^{2}$ - Francesc \\ Rocadenbosch $^{3,4}$ • Ourania Soupiona ${ }^{2}$ - Panagiotis-Ioannis Raptis ${ }^{5}$ - Maria \\ Mylonaki² $~$ Chris G. Tzanis $^{6}$ • John Christodoulakis ${ }^{6}$
}

Received: DD Month YEAR/ Accepted: DD Month YEAR

\begin{abstract}
We investigate the temporal evolution of the planetary boundary-layer (PBL) height over the basin of Athens, Greece, during a 6-year period (2011-2016), using data from a Raman lidar system. The range-corrected lidar signals are selected around local noon (1200 UTC) and midnight (0000 UTC), for a total of 332 cases: 165 days and 167 nights. In this dataset, the extended-Kalman filtering technique is applied and tested for the determination of the PBL height. Several well-established techniques for the PBL height estimation based on lidar data are also tested for a total of 35 cases. The lidar-derived PBL heights are compared to those derived from radiosonde data. The mean PBL height over Athens is found to be $1617 \pm 324 \mathrm{~m}$ at $1200 \mathrm{UTC}$ and $892 \pm 130 \mathrm{~m}$ at 0000 UTC for the period examined, while the mean PBL-height growth rate is found to be $170 \pm 64 \mathrm{~m} \mathrm{~h}^{-1}$ and $90 \pm 17 \mathrm{~m} \mathrm{~h}^{-1}$ during daytime and night-time, respectively.
\end{abstract}

\footnotetext{
$凶$ Panagiotis Kokkalis

panagiotis.kokkalis@ku.edu.kw

1 Physics Department, Kuwait University, P.O. Box 5969, Safat, 13060, Kuwait

2 Laser Remote Sensing Unit (LRSU), Physics Department, National Technical University of Athens, Zografou, 15780, Greece

3 CommSensLab-UPC, Department of Signal Theory and Communications, Universitat Politècnica de Catalunya, E-08034 Barcelona, Spain

4 Institute of Space Studies of Catalonia, Universitat Politècnica de Catalunya, E-08034 Barcelona, Spain

5 Institute for Environmental Research and Sustainable Development, National Observatory of Athens, Penteli, 15236 Athens, Greece

6 Section of EnvironmentalPhysics and Meteorology, Department of Physics, Nationaland Kapodistrian University of Athens, 15784 Athens, Greece
} 
Keywords Extended-Kalman filter, Lidar signal, Planetary boundary layer

\section{Introduction}

The planetary boundary layer (PBL) is the lowest part of the troposphere (Stull 1988) and the knowledge of its height $\left(R_{b l}\right)$, is important since air pollutants are trapped within this physical atmospheric barrier, thus affecting the population's health, and also that of plants and animals. Therefore, the knowledge of the PBL's height information is a crucial input parameter to atmospheric models, in order to describe realistically the lower atmospheric dynamics and provide accurate and real-time air-pollution dispersion forecasts. However, PBL height modelling remains one of the major causes of uncertainty in forecasting atmospheric conditions and air pollution (i.e., Pleim 2007). Thus, there is a need for further investigation of PBL structure, its development and dynamics. The determination of the PBL height by atmospheric measurements is not a trivial task. For this scope, various methods have been explored through the years by using a variety of scientific instruments, with the most common source of data to be from weather balloons and lidars (cf. Tsaknakis et al. 2011).

Radiosondes are widely distributed spatially, with their data to be subjected to quality control on a continual basis. Although they can provide vertical profiles of meteorological parameters with high accuracy, they demonstrate the following disadvantages: (a) the collected data refer to a specific time period, of the order of a few minutes, from the time of launching, (b) in the case of strong winds in the upper atmosphere, the balloon trajectory may drift and the collected data may refer to a geolocation far away from the launching site, and (c) they are costly on an operational basis.

On the other hand, lidar instruments have also been used extensively for determining the top of the PBL and they are not subject to the aforementioned limitations (Melfi et al. 1985; Menut et al. 1999; Sicard et al. 2006). The majority of the developed techniques are based on the unique capability of the lidar systems to provide continuous vertical profiles of aerosols, which can be used as tracers to determine the PBL height temporal variation. However, the existing lidar-based techniques may be affected by specific atmospheric conditions, leading to retrievals with high uncertainties. Such specific atmospheric 
conditions are related to: (a) the presence of clouds, (b) the presence of low aerosol load in the atmosphere, and (c) complex atmospheric structures, especially when free troposphere aerosols entrain the boundary layer. In the last few years, a new approach has been developed for estimating the PBL height, namely, the extended-Kalman filtering (EKF) technique (Lange et al. 2014), which uses the range-corrected lidar signal (RCS). The EKF technique employs simplified statistics of the noise introduced on the observed lidar signal and of the PBL dynamics in order to analyze atmospheric scenes even with low signal-tonoise ratios and under short-time averaging windows (Lange et al. 2014).

In this study, the EKF technique is used to test against other established techniques for the first time and is applied on a six-year-long dataset of lidar measurements (2011-2016) obtained over the complex environment of the megacity of Athens, Greece, for the

estimation of the PBL height, and the corresponding growth rate $\left(\frac{\Delta R_{b l}}{\Delta t}\right)$ under various atmospheric conditions. More precisely, our methodology and instrumentation are presented in Sects. 2 and 3, with extended case studies examined in Sect. 4. Additionally, statistical values of the PBL height and the corresponding growth rate are estimated over the time period of our study. Our conclusions are provided in Sect. 5.

\section{Methodology}

The top of the boundary layer in convective conditions is often well defined by the existence of an entrainment zone into which turbulent motions from beneath are unable to penetrate far (though they may continually erode it especially when latent heat is released in rising elements of air). The height of this elevated stable layer is quite variable, but is generally below $2-3 \mathrm{~km}$. On the contrary, under stable conditions the boundary layer is not so readily identified, turbulence is much weaker compared to the unstable case, and consequently the depth is no more than a few hundred metres at most. At night over land, under clear skies and light winds, it may be even lower and its final depth is strongly influenced by internal wave motions (Stull 1988).

Several methods and criteria have been used to retrieve the PBL height by utilizing data retrieved from both radiosondes and lidar instruments. Regarding the weather balloon data, the parameters of humidity, potential temperature, and bulk Richard son number are used (e.g., Seidel et al. 2010). With respect to the lidar technique, aerosols can be used as tracers 
for the atmospheric motion and, therefore, for the study of the PBL structure. The most common methods are the: (a) derivative-based methods (Sicard et al. 2006), (b) the threshold method (Melfi et al. 1985), (c) the variance method (Menut et al. 1999), and (d) the wavelet-covariance-transform method (Baars et al. 2008). In this section, we briefly describe the methodology.

\subsection{Planetary Boundary-Layer Height Retrieval From Radiosondes}

Seibert et al. (2000) provide a comparison of the benefits and caveats of various observational methods used to determine the PBL height. According to Garratt (1994), the top of the PBL is located at the point where the gradient of the potential temperature becomes maximum, since there is a transition from an unstable area to a stable. Another important atmospheric parameter, such as the relative humidity, also has been used for determining the PBL height. The identification of the boundary-layer top is based on the air moisture condition differences observed below and above the boundary layer. Since passive scalars are accumulated in the boundary layer, and therefore large gradients of water vapour density occur at the inversion capping, it is typical to use that gradient for defining the top of the PBL. However, the presence of clouds may introduce high uncertainties in the PBL height retrieval (Seidel et al. 2010).

Here, the top of the PBL is recognized as the height at which the bulk Richardson number $\left(\gamma_{R i}\right)$ becomes equal to the critical value $\left(\gamma_{R i, c}\right)$, typically between $0.1-1.0$ (Richardson et al. 2013). The bulk Richardson number profile is calculated as (Menut et al. 1999)

$$
\gamma_{R i}(R)=\frac{g\left(R-R_{O}\right)\left[\left(\theta(R)-\theta\left(R_{O}\right)\right)\right]}{\theta(R)\left[\left(u(R)^{2}+v(R)^{2}\right)\right]}
$$

where $\theta$ is the virtual potential temperature, $R$ is the height above ground, $R_{o}$ is the height of the surface, $g$ is the gravitational acceleration, and $u$ and $v$ are the zonal and meridian velocity components, respectively. In the literature many studies report various values of $\gamma_{R i, c}$ (e.g. Vogelezang and Holtslag 1996; Sørensen et al. 1996), with discussion of an ideal value of $\gamma_{R i, c}$ (e.g. Esau and Zilitinkevich 2010; Zhang et al. 2014). The aforementioned studies, along with many others, are summarized in Zilitinkevich and Baklanov (2002). 
Here, we employ the bulk Richard son number method by setting the critical value equal to 0.25, which is a common threshold for the area of Athens (Banks et al. 2016).

\subsection{Planetary Boundary-Layer Height Retrieval From Lidar Signals}

\subsubsection{The Extended-Kalman Filter}

The Kalman filter is an adaptive filter inherited from classic control theory (Kalman 1960), which enables the state vector of a dynamic linear system to be estimated and tracked with time (e.g., position coordinates of an aircraft). This filter can also be applied to non-linear systems, as is the case here, via linearization, which gives rise to the EKF technique. The filter operates by minimizing the error between the estimated and the true state vector (unknown) in a mean-square error sense over time. Because the filter makes use of not only present information (the measurements) but also past estimates, as well as related covariance statistics, it provides an optimal solution over time. Recently, Lange et al. (2014, 2015) departing from earlier work (Rocadenbosch et al. 1998, 1999), have successfully applied the extended-Kalman filtering technique to estimate the daytime PBL height from tropospheric backscattered lidar and radar signals, respectively.

In lidar applications, the EKF technique uses range-corrected backscatter returns $R C S(R)$, at successive discrete times, $t_{k}$ (in what follows, the "observables", $\mathbf{z}_{\mathbf{k}}$, with $k$ a reminder of discrete time; formally, $\mathbf{z}_{\mathbf{k}}(R), R$ omitted for brevity) as a proxy of the total backscatter coefficient and, in turn, of the atmospheric (aerosol) load (note that "range" and "height" are used interchangeably because of the vertical pointing direction of the lidar). Central to the method is the assumption of an abrupt mixing-layer to freetroposphere transition in the profile of lidar backscatter return, $\operatorname{RCS}(R)$, which is modelled by an erf-like function (Fig. 1). The morphology of the erf function in Fig. 1 gives rise to the state vector,

$$
\mathbf{x}_{\mathbf{k}}=\left[R_{b l, k}, a_{k}, A_{k}, c_{k}\right]^{t},
$$

to be estimated at each recursive loop of the filter (bold font denotes vector notation). 


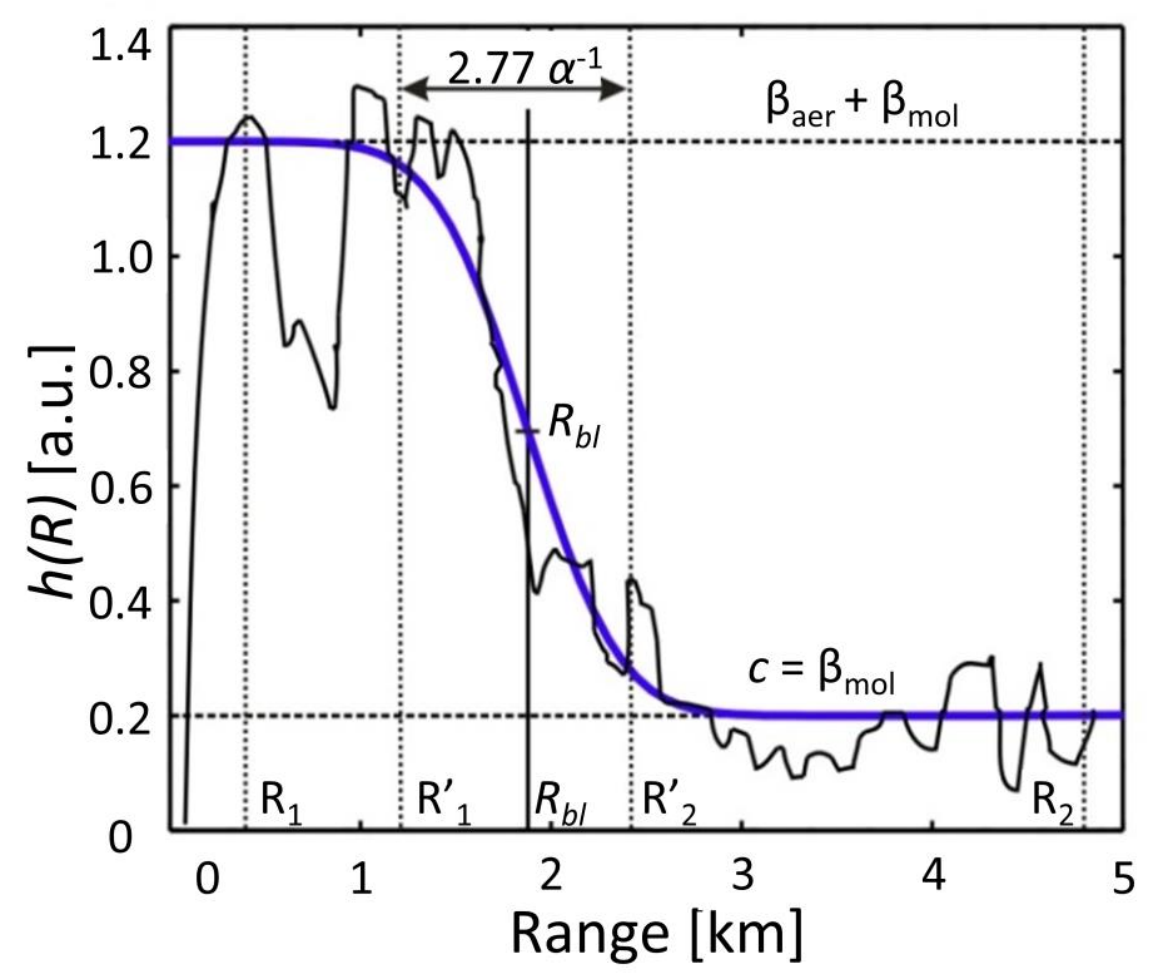

Fig. 1 The erf-like transition model. $h(R)$ is the erf-like function of Eq. (5), $R_{b l}$ is the PBL height, $\alpha$ is the form factor related to the entrainment-zone thickness $\left(2.77 \alpha^{-1}\right), A$ is the mixing-layer to free-troposphere transition amplitude, and $c$ is the free-troposphere molecular background (adapted from Banks et al. 2016)

The filter requires two models to operate. The first is the state-vector model, in which the dynamics of the state-vector from time $t_{k}$ to time $t_{k+1}$ are modelled using a GaussMarkov transition model,

$$
\mathbf{x}_{\mathrm{k}+1}=\mathbf{x}_{\mathrm{k}}+\mathbf{w}_{\mathrm{k}}
$$

where $\mathbf{w}_{\mathbf{k}}$ is the so-called "process noise" or state-noise vector. Because the state vector $\mathbf{x}_{\mathbf{k}}$ (to be estimated) is a hidden "state" of the atmosphere, additional information is needed from the user's side: (a) an initial guess, $\widehat{\mathbf{x}_{\mathbf{0}}^{-}}=\left[R_{b l, 0}, a_{0}, A_{0}, c_{0}\right]^{t}$, and (b) an estimate of the process-noise covariance matrix, $\mathbf{Q}_{\mathbf{k}}=E\left[\mathbf{w}_{\mathbf{k}} \mathbf{w}_{\mathbf{k}}^{\mathbf{t}}\right]$.The latter is approximated in diagonal form by $\mathbf{Q}_{\mathbf{k}}=\operatorname{diag}\left[\boldsymbol{\sigma}_{\mathbf{Q}}^{2}\right], \boldsymbol{\sigma}_{\mathbf{Q}}=\left(\sigma_{R b l}, \sigma_{a}, \sigma_{A}, \sigma_{C}\right)$, the latter built from a user-defined intensity factor, $\boldsymbol{\mu}_{\mathbf{Q}}$, so that $\boldsymbol{\sigma}_{\mathbf{Q}}=\mu_{Q} \widehat{\mathbf{x}_{\mathbf{0}}^{-}}$. For example, $\sigma_{R b l}$ roughly models the expected stand ard deviation of the $h$ around its mean value. The filter also requires initialization of the a priori error covariance matrix, $\mathbf{P}_{\mathbf{k}}^{-}=E\left[\mathbf{e}_{\mathbf{k}}^{-} \mathbf{e}_{\mathbf{k}}^{-\mathbf{t}}\right]$, where $\mathbf{e}_{\mathbf{k}}^{-}=\mathbf{x}_{\mathbf{k}}-\hat{\mathbf{x}}_{\mathbf{k}}^{-}$is the error vector and $\hat{\mathbf{x}}_{\mathbf{k}}^{-}$is the estimated a priori state vector (i.e., prior to assimilating the current measurement at time $\mathbf{t}_{\mathbf{k}}$ ). In such initialization, $\mathbf{P}_{\mathbf{0}}^{-}$, models the expected error on the state- 
vector initial guess and is provided in the form $\mathbf{P}_{\mathbf{0}}^{-}=\operatorname{diag}\left[\boldsymbol{\sigma}_{\mathbf{e}, \mathbf{X}}^{\mathbf{X}}\right]$, with $\boldsymbol{\sigma}_{\mathbf{e}, \mathbf{X}}=$ $\left(\sigma_{e, R b l}, \sigma_{e, a}, \sigma_{e, A}, \sigma_{e, c}\right)$ the user's uncertainty on the state-vector components at time $t_{0}$. Likewise, the latter is passed to the filter as an a priori error factor, $\mu_{P}$, so that $\boldsymbol{\sigma}_{\mathbf{e}, \mathbf{X}}=\mu_{P} \widehat{\mathbf{x}_{\mathbf{0}}^{-}}$.

The second model is the measurement model, which relates the state-vector, $\mathbf{x}_{\mathbf{k}}$ with the measured observables, $\mathbf{z}_{\mathbf{k}}$,

$$
\mathbf{z}_{\mathbf{k}}=\mathbf{h}\left(\mathbf{x}_{\mathbf{k}}\right)+\mathbf{v}_{\mathbf{k}}
$$

where

$$
\mathbf{h}\left(\mathbf{x}_{\mathbf{k}}\right)=\frac{A_{k}}{2}\left\{1-\operatorname{erf}\left[\frac{a_{k}}{\sqrt{2}}\left(R-R_{b l, k}\right)\right]\right\}+c_{k}
$$

is the erf function of Fig. 1 and $\mathbf{v}_{\mathbf{k}}$ is the observation noise at time $t_{k}$ with covariance matrix, $\mathbf{V}_{\mathbf{k}}$ (diagonal). $\mathbf{V}_{\mathbf{k}}$ is estimated by computing the range-dependent observation noise variance from the range-dependent signal-to-noise ratio, $\operatorname{SNR}(R)$ (Lange et al. 2015).

\subsubsection{Common Methods}

The estimation of the PBL height from lidar measurements is based on the fact that the aerosol load entrapped below the PBL is significantly higher than the free tropospheric aerosol load. In the following, we briefly describe the general characteristics of the most common techniques that are used for the determination of the PBL height.

The wavelet covariance transform (WCT) technique (Hooper and Eloranta 1986) has proved to be one of the most reliable methods for detecting the top of PBL (Baars et al. 2008). The WCT technique is defined as (Brooks 2003)

$$
W_{f}(R)=\frac{1}{a} \int_{R_{b}}^{R_{t}} f\left(R^{\prime}\right) \mathcal{H}\left(\frac{R-R^{\prime}}{a}\right) d R^{\prime},
$$

with $\mathcal{H}$ the Haar function (so-called Haar's wavelet): 


$$
\mathcal{H}\left(\frac{R-R^{\prime}}{a}\right)=\left\{\begin{array}{rr}
-1 & R^{\prime}-\frac{a}{2} \leq R<R^{\prime} \\
+1 & R^{\prime} \leq R<R^{\prime}+\frac{a}{2} \\
0 & \text { elsewhere. }
\end{array}\right.
$$

In Eq. 6 above, $f(R)$ is the RCS, and $R_{b}$ and $R_{t}$ are the lower and upper height limits of the lidar return signal profile, respectively. Moreover, dilation parameter $a=\eta \Delta R$ (where $\eta$ is an integer and $\Delta R$ is the height resolution of lidar) defines the extent of wavelet function $\mathcal{H}$, while translation parameter $R^{\prime}$ determines the centre location of the function. $W_{f}(R)$ represents the measure of similarity between the Haar's function and the RCS. Alternatively, $W_{f}(R)$ can be understood as the low-pass filtered version of the RCS. It has been shown that the WCT method using Haar's wavelet is completely equivalent to the gradient method applied to a spatially low-pass filtered range-corrected signal (Comerón et al. 2013). In the WCT method, the lowest height of a local maximum of variance profile $W_{f}(R)$ is identified at the top of the PBL. Proper choice of upper and lower range limits of integration as well as the value of the dilation parameter are the most critical factors for the success of the method. The dilation is ideally equal to the depth of the transition zone, which, however, usually is unknown.

One of the very first methods developed and used for the determination of the PBL height was the threshold method (THR) (Melfi et al. 1985; Boers and Eloranta 1986). In this technique, a critical level of the RCS, which corresponds to the RCS value at the PBL top height, has to be defined. Moreover, the user has to select an upper and a lower search height for that threshold value.

Another widely used method is the variance technique (VAR), in which the PBL top is defined as the height where the variance of the RCS becomes maximum (Menut et al. 1999). Formally,

$$
R_{b l}^{V A R}=\max _{R}\left\{\frac{1}{N} \sum_{i=1, N}\left[R C S_{i}(R)-\overline{R C S}(R)\right]^{2}\right\},
$$

where $\mathrm{RCS}_{\mathrm{i}}$ is the $i$-th range-corrected signal profile and $\overline{\mathrm{RCS}}$ is the mean profile. The number of lidar signal profiles for the calculation of the variance and the upper and lower height limits are chosen from the user's side. 
The gradient method (GM) is the simplest method that estimates the PBL height by finding the height at which there is an absolute local minimum of the first derivative of RCS as a function of height (Sicard et al. 2006),

$$
R_{b l}^{G M}=\min \left[\frac{\partial(R C S)}{\partial R}\right]
$$

where RCS is the range-corrected signal and $R$ is height. Similarly, for the so-called logarithmic gradient method (LGM), the logarithm of the RCS is used. The PBL height is defined as the height where an absolute local minimum of the first derivative of the $\ln (\mathrm{RCS})$ is attained,

$$
R_{b l}^{L G M}=\min \left\{\frac{\partial[\ln (R C S)]}{\partial R}\right\} .
$$

Similarly, the inflection point (IPM) estimates the PBL height as the height where an absolute local minimum of the second derivative of RCS is found (Menut et al. 1999),

$$
R_{b l}^{I P M}=\min \left[\frac{\partial^{2}(R C S)}{\partial R^{2}}\right] .
$$

For the case studies presented later on (see Sect. 4.1) and for each of the methods described above we used one single acquisition of the lidar signal, which corresponds to $1.66 \mathrm{~min}$. This was done in order to compare the classic methods with the EKF and demonstrate the efficiency of each method on an operational basis. However, for the statistical results presented in Sect. 4.3 a mean lidar profile is used, which is calculated within $\pm 30 \mathrm{~min}$ from 1200 and 0000 UTC, respectively. A cross-examination of these classic methods can be found in Fig. 3 of Lange et al. (2014).

\section{Instrumentation}

\subsection{Location}

Athens (Greece), is hosting approximately $40 \%$ of the country's population. The Greater Athens area includes the cities of Athens and Piraeus along with their suburbs, and lies in a basin surrounded by mountains from three directions and the sea from the fourth (Fig. 2). The three main mountains are the Hymettous to the north-north-east, Parnitha to the northnorth-west, and Aegaleo to the west, with elevations up to 1050,1400 , and $450 \mathrm{~m}$ 
respectively, acting like physical barriers making an opening towards the Saronic Gulf to the west.

The atmospheric circulation within the Athens basin results from the interaction of various scales: synoptic, regional, meso, and microscale. During winter months the dispersion conditions in the Greater Athens area are associated with the strength of the pressure system over the central Mediterranean and the Aegean Sea. During summer months, these conditions depend on the relative strength of the high-pressure system covering the Eastern Mediterranean and Balkan area and the balance between this system and the thermal low over the Anatolian Plateau. Understrong pressure gradient conditions, northerly winds dominate, creating good ventilation in the Athens basin. This wind pattem consists of a regional-scale phenomenon called etesians. During the transient periods of autumn and spring, weather conditions change regularly between winter and summer type. For a summary of the synoptic conditions see Kallos et al. (1993). Local circulations (e.g., sea (land)-breeze) are usually observed during days of relatively weak synoptic flow. Seabreeze circulations develop during more than $30 \%$ of the days of the spring and summer months, but such events are also reported during winter (Prezerakos 1986). They play a significant role in determining the diurnal variation and strength of photochemical pollution and PBL height. The sea-breeze flowing over the Athens basin usually originates from the Saronic Gulf, with west-south-west to south surface winds during the day and north winds during the night. Additionally, when the air flow is entering the area from the sea side (south and south-east), the formation of an internal boundary layer (IBL) can be observed (Garratt 1990). The height of the IBL in the study area under sea-breeze conditions is expected up to $450 \mathrm{~m}$, which is confirmed both by experimental (Melas and Kambezidis 1992) and modelled simulation studies (Batchvarova and Gryning 1998). A detailed analysis of the climatological observations from the Greater Athens area can be found in Kassomenos et al. (1995).

\subsection{Lidar Unit}

The Laser Remote Sensing Unit (LRSU) of the National Technical University of Athens (NTUA), is based in Athens $\left(37.96^{\circ} \mathrm{N}, 23.78^{\circ} \mathrm{E}\right.$, elev. $220 \mathrm{~m}$ a.s.1.) (Fig. 2). The LRSU is equipped with an advanced six-wavelength elastic-Raman lidar system EOLE (aErosol and 
Ozone Lidar systEm), able to perform independent and simultaneous measurements of the vertical profiles of the aerosol backscatter coefficient (at 355, 532, and $1064 \mathrm{~nm}$ ), the aerosol extinction coefficient (at 355 and $532 \mathrm{~nm}$ ), and the water vapour mixing ratio in the troposphere using the $\mathrm{H}_{2} \mathrm{O}$ Raman channel at $407 \mathrm{~nm}$ (Kokkalis et al. 2012).

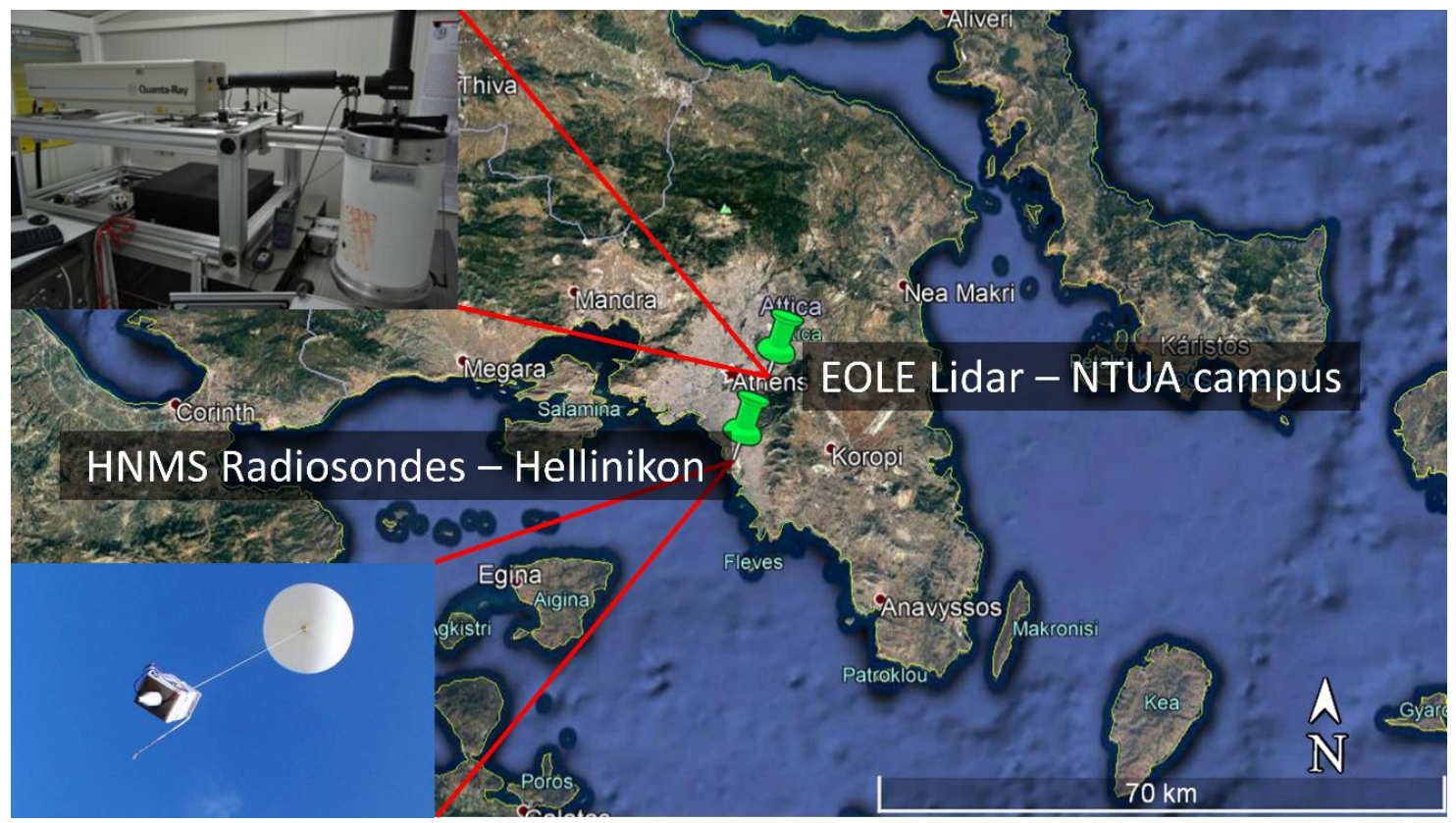

Fig. 2 Map of Greater Athens area in Greece, showing the locations of the ela stic-Ra man lidar(EOLE) system and the radiosonde launching site (HNMS)

The EOLE system is based on a pulsed Nd:YAG laser system which emits, simultaneously, high energy pulses at 355, 532, and $1064 \mathrm{~nm}$, with a $10-\mathrm{Hz}$ repetition frequency. The system is designed following the optical set-up (Kokkalis 2017) of a typical member station of the European Aerosol Research Lidar Network (EARLINET), meeting all the quality assurance requirements of the network (Amodeo et al. 2018). A 300-mm Cassegrainian telescope collects the backscattered lidar signals, as well as those generated by the spontaneous Raman effect. The 12-bit analog-to-digital conversion system can store up to 4000 signal records of 8000 time bins each. However, in the case of a single acquisition only 1000 lidar returns were averaged, which means a time resolution of 1.66 min. Additionally, because the acquisition frequency is $20 \mathrm{MHz}$, i.e., one time bin equals $t_{d}=50 \mathrm{~ns}$ detection time, and the laser pulse width is much shorter that the detection time, 
the spatial resolution becomes $\Delta R=c \frac{t_{d}}{2}=7.5 \mathrm{~m}$. Afterwards, the lidar signals are preprocessed and corrected for the electronic and atmospheric background noise, prior to the retrieval of the RCS given in arbitrary units (a.u.). The RCS used here does not need to be calibrated with respect to the lidar constant, since no system modifications were made during the measurement period used in this study.

\subsection{Radiosondes}

Meteorological radiosondes are launched on a regular basis by the Hellenic National Meteorological Service (HNMS) at the Hellinikon site $\left(37.88^{\circ} \mathrm{N}, 23.73^{\circ}\right.$ E, elev. $15 \mathrm{~m}$ a.s.l.), located approximately $12 \mathrm{~km}$ south-west of the LRSU station. The HNMS is using Vaisala radiosondes (model RS92-SGP) to retrieve the vertical profiles of atmospheric pressure, relative humidity, air temperature, as well as wind speed and direction. The relative humidity uncertainty is estimated down to $4 \%$ (Dirksen et al. 2014), with higher values in the mid and high troposphere due to radiation dry bias and significantly fewer errors in the PBL (Vömel et al. 2007). The temperature uncertainties are up to $0.7 \mathrm{~K}$ during daytime and up to $0.4 \mathrm{~K}$ during night-time (Dirksen et al. 2014). Additional information related to the radiosondes and the launching site can be found in Papayannis et al. (2017) and Labzovskii et al. (2018).

\section{Experimental Results}

In order to evaluate the overall performance of the EKF technique, we proceed with a comparative analysis, among the most commonly used techniques for the determination of the PBL height. In total, seven methods based on lidar signals (i.e., EKF, VAR, GM, LGM, IMP, THR, and WCT) were compared against the PBL height estimations from radiosonde data (with bulk Richard son number threshold), which were considered to be our reference.

In the first part of this section we present seven case studies demonstrating the capabilities of the methods used. The selected case studies are representative of different types of atmospheric-aerosol conditions prevailing over the study area, and include cases 
of PBL decoupled dust layers, etesian winds, clouds, sea-breeze, nocturnal boundary layer (with and without distinguishable residual layer), as well as clear tropospheric conditions.

Later on, we extend our analysis on a statistical base for the estimations of the PBL height $\left(R_{b l}\right)$ and growth rate $\left(\frac{\Delta R_{b l}}{\Delta t}\right)$. Our dataset (January 2011-October 2016) is carefully examined in order to avoid using days with scattered clouds, which can lead to neutral atmospheric conditions.

\subsection{Case Studies}

The main advantage of the EKF method is the assimilation of previous estimations in order to retrieve the PBL height at the present time. This makes the technique an excellent candidate fornear real-time operation that can work extremely well in cases where different layers exist (e.g., nocturnal and residual layers) provided that minimal morphological differences exist among these layers. At the same time, the aforementioned advantage can lead to misleading results, especially in cases where the aerosol load changes rapidly (e.g., sea-breeze conditions).

The WCT method can work on an operational basis too. In order to optimize its performance, we can constrain the upper and lower height limits of the algorithm (Cohn and Angevine 2000), but in that case the operational capability is lost. Regarding the VAR method, it is clear that in specific cases (e.g., clouds) the method fails because the peak variance is found at the top of the layer. As far as the THR method is concerned, it cannot operate continuously since very frequently an appropriate signal threshold must be sought. Besides, the THR method has limited capabilities in cases where the aerosol load inside the PBL is not well stratified (e.g., etesian case), which leads to an underestimation of the PBL height. However, the THR method shows great performance in a well-mixed PBL. Finally, the gradient-based methods cannot either be successful under continuous operation since frequent adjustments of the upper and lower height limits must be done. This is the case of dust layers decoupled from the PBL, where it can be difficult for these methods to find the minimum of the derivative of the signal. However, the GM method can perform 
better than the LGM/IPM methods since in the latter ones, corrupting noise is boosted by the logarithm and the second-derivative operators, respectively (Lange et al. 2014).

\subsubsection{Case Study I: Dust}

Dust transport events over the Mediterranean region are usually observed over southern Europe due to cyclonic winds (Escudero 2005; Kallos et al. 2006; Schepanski and Knippertz 2011; Fiedler et al. 2014; Flaounas et al. 2015). Especially over the Eastern Mediterranean, the transportation of Saharan dust is favoured during spring and summer months (Papayannis et al. 2008; Gerasopoulos et al. 2009; Soupiona et al. 2018).

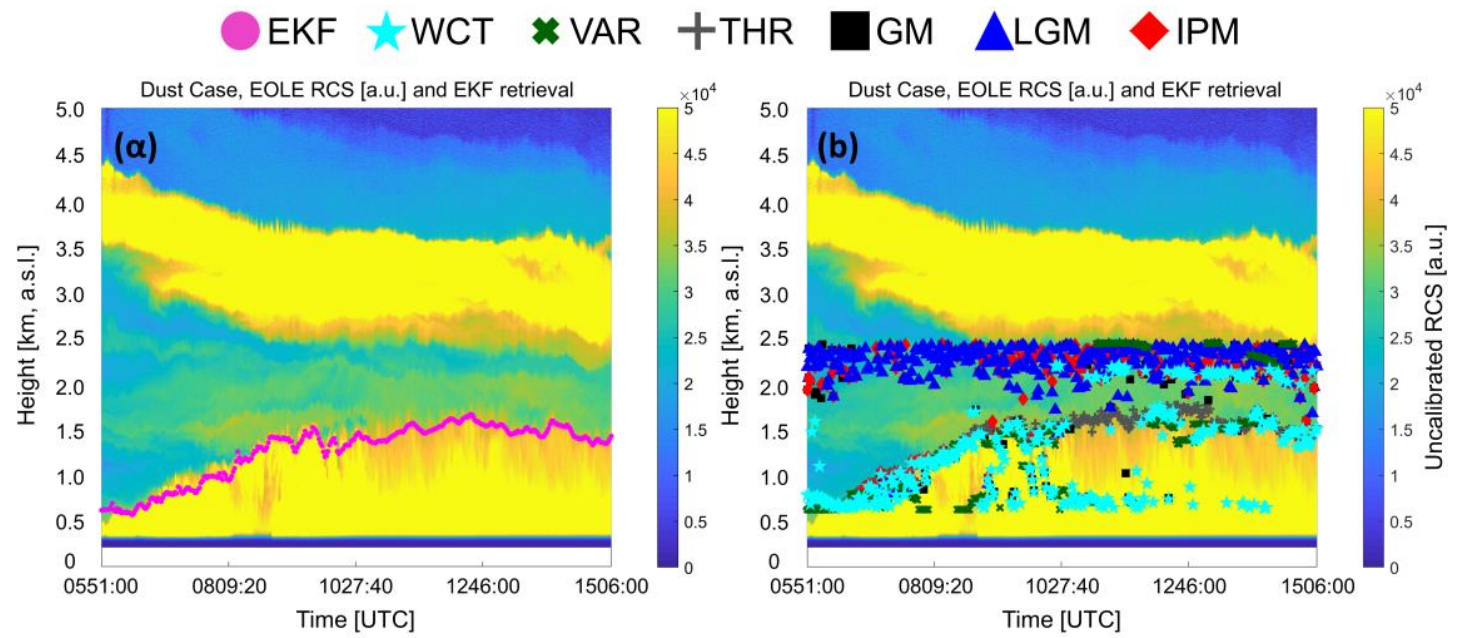

Fig. 3 Spatio-temporalevolution of EOLE RCS (in a.u.) and PBL height estimates during a dust case study over Athens: (a) EKF estimates (pink dots), (b) Classical-methods estimates: WCT, turquoise stars; VAR, green $x$; THR, grey crosses; GM, black squares; LGM, red rhombuses; IPM, blue triangles 
A representative case study (26 May 2014) of free tropospheric dust observation is presented

in

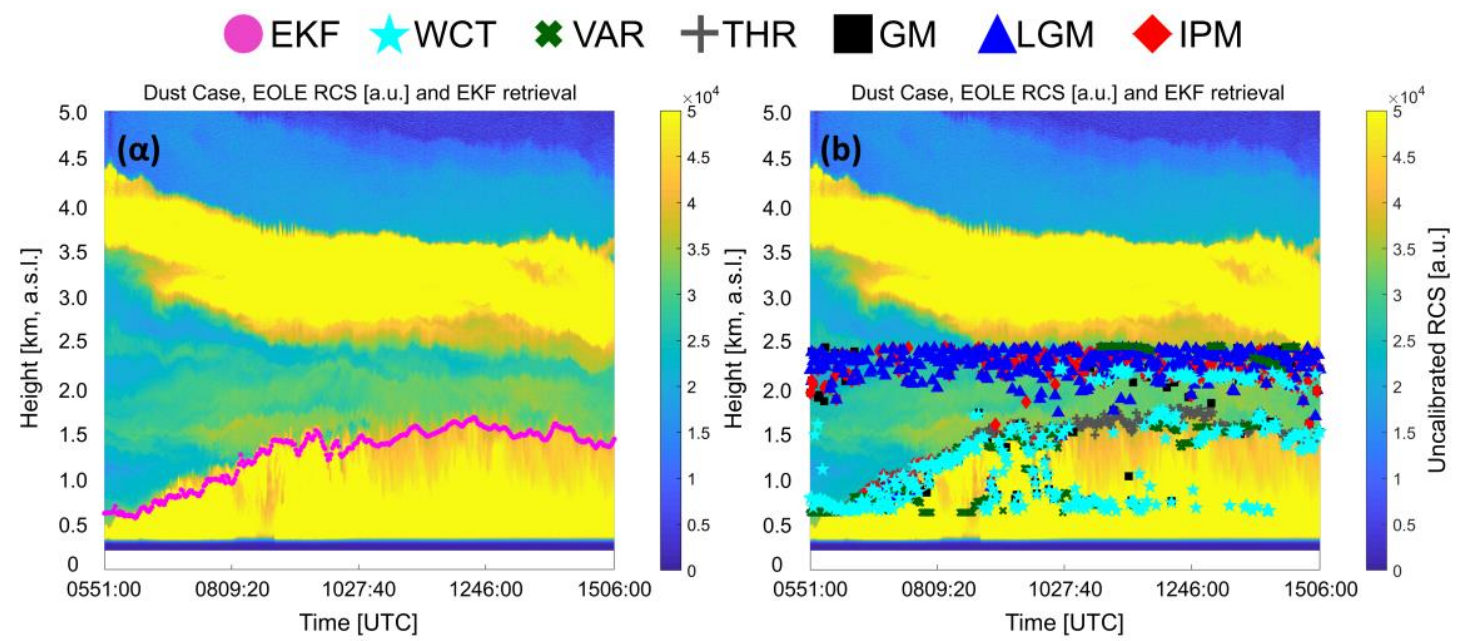

Fig. 3. The spatio-temporal evolution of the RCS obtained during 0551-1506 UTC is showing a free tropospheric Sahara dust layer of approximately 1500-m thickness, with a center of mass at around $3000 \mathrm{~m}$. The PBL seems to be fully developed by 1300 UTC, 
taking a maximum value of about $1600 \mathrm{~m}$ a.s.l., according to the EKF method (

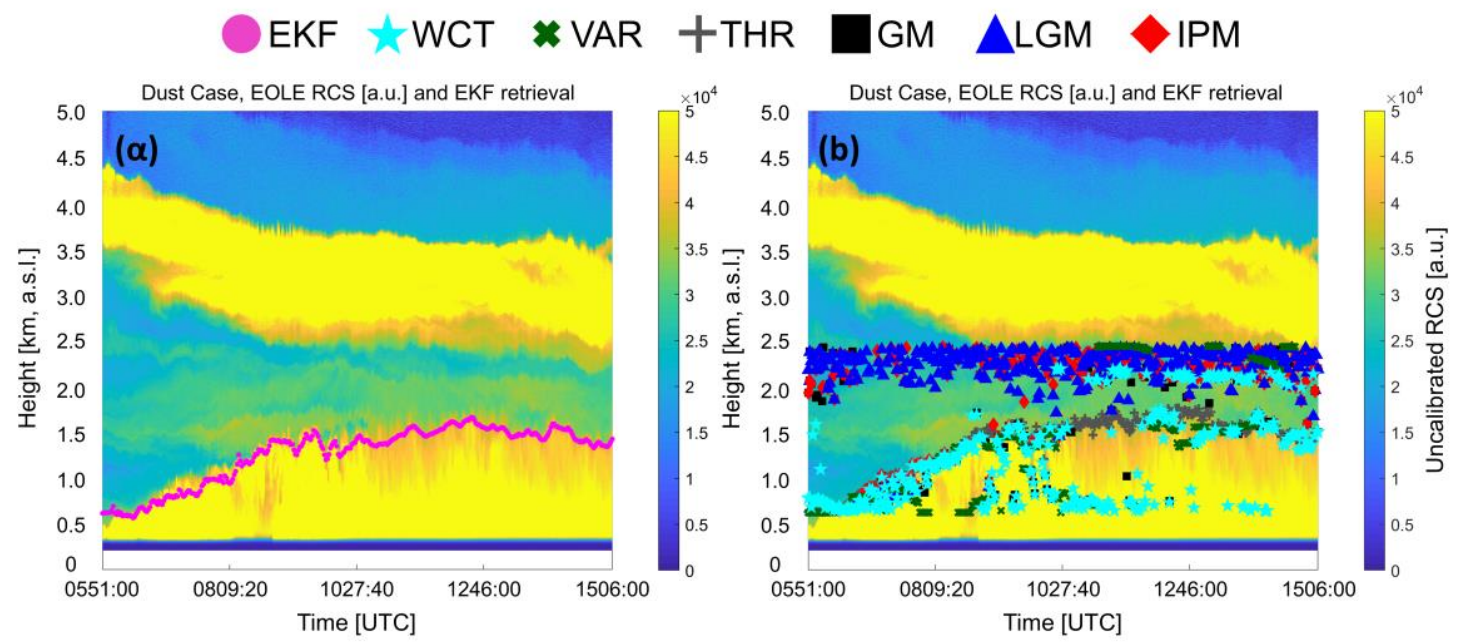

Fig. 3a). As we will see later (see Sect. 4.3), this value is lower than the statistical mean PBL height of May (1749 m).

The PBL height obtained by the radiosonde at 1200 UTC is $1561 \mathrm{~m}$. In

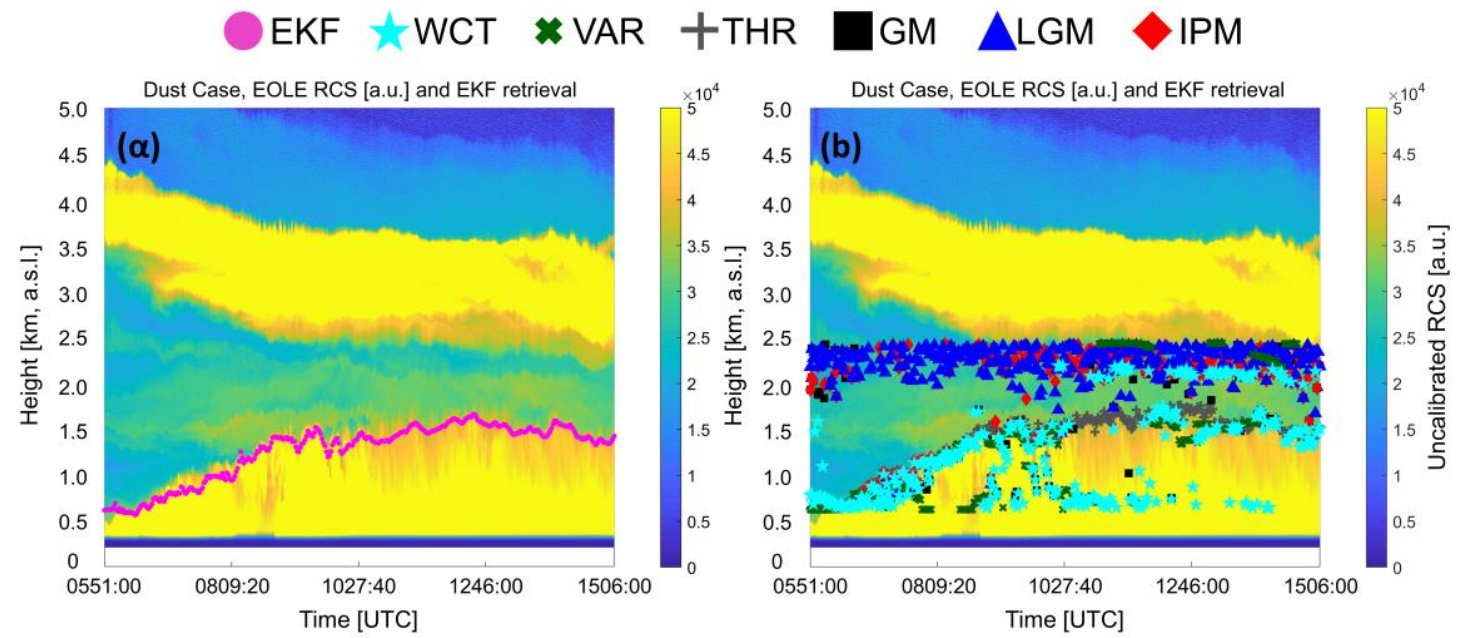

Fig. 3 the EKF method seems to provide the closest PBL height estimate to the radiosounding $(1512 \mathrm{~m})$ at that time. All other methods, apart from IPM, successfully determine the PBL height at 1200 UTC. Thus, WCT/THR/VAR methods show similar estimates around $1632 \mathrm{~m}$ while GM/LGM methods determine the PBL height at $2169 \mathrm{~m}$, and the IPM at $2377 \mathrm{~m}$. Apart from the THR and EKF methods, all others are affected by the presence of the thick free-troposphere layer near to the boundary-layer top.

\subsubsection{Case Study II: Etesian}


From about mid-May to mid-September, the high pressure over the Balkans and south-east Europe along with a thermal low-pressure system over Asia result in the development of strong and dry etesian winds in the lower troposphere of the Aegean Basin (e.g., Metaxas and Bartzokas 1994; Poupkou et al. 2011; Tyrlis et al. 2014). This synoptic flow pattem can also force distinct sea currents and eddies over the entire Levantine basin (Zecchetto and De Biasio 2007) and in turn affect marine and coastal environments. Furthermore, the pronounced topography over the Eastern Mediterranean sustains and accelerates the north direction of the etesian flow, with the wind speed often exceeding $15 \mathrm{~m} \mathrm{~s}^{-1}$ (Kotroni et al. 2001; Tombrou et al. 2015). A representative case (04 September 2011) is shown in Fig. 4. During this day, the aerosol load entrapped within the PBL is significantly decreased due to strong low altitude winds advecting airborne pollutants from the land towards the sea.

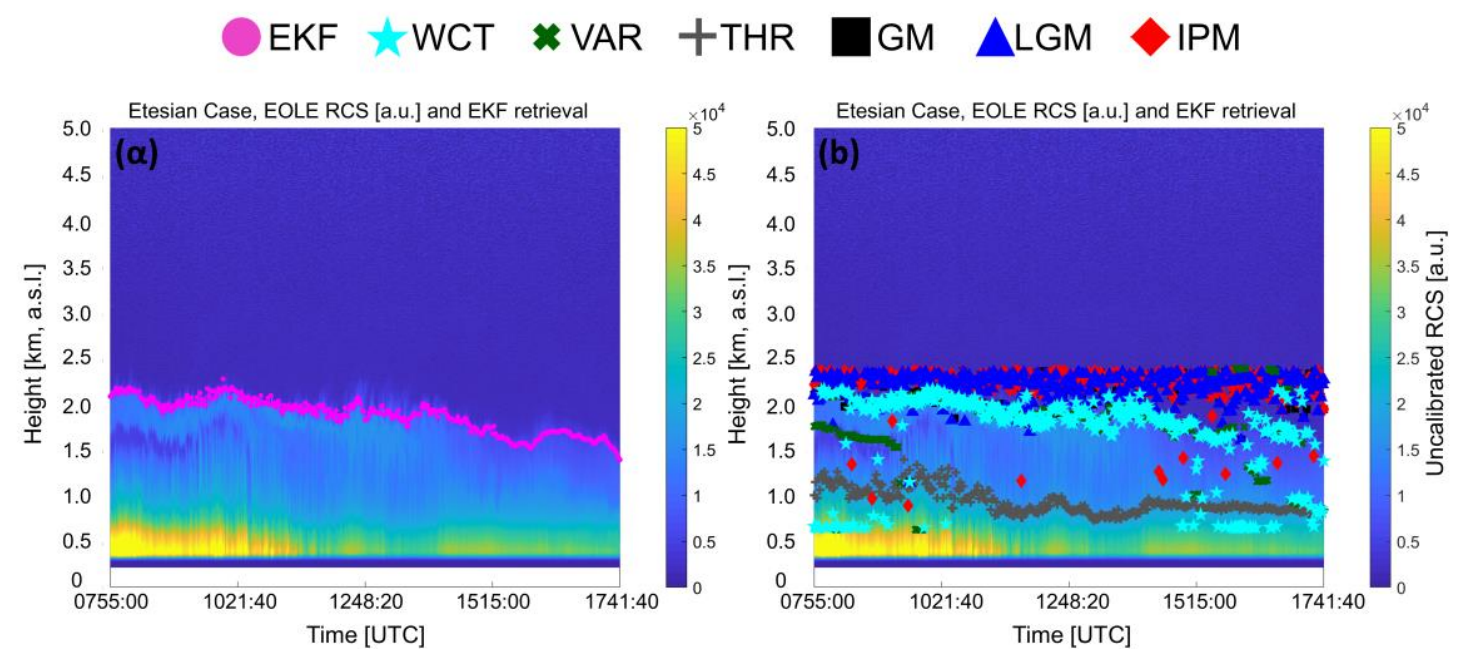

Fig. 4 Spatio-temporal evolution of EOLE RCS (in a.u.) and PBL height estimates during a case study of etesian winds over Athens: (a) EKF estimates (pink dots), (b) Classical-methods estimates: WCT, turquoise stars; VAR, green x; THR, grey crosses; GM, black squares; LGM, red rhombuses; IPM, blue triangles

The decreased aerosol load in combination with the strong eddies developed in the lower troposphere are two factors that make the determination of the PBL height by lidar methods quite difficult. The boundary layer grows up to $2122 \mathrm{~m}$ at 1024 UTC (solar noon) according to the EKF technique. The estimation of the PBL height by the radiosonde is found to be $1993 \mathrm{~m}$ at 1200 UTC. Lidar-based PBL height retrievals were compared to the 
radiosonde and found that the closest one was provided by the EKF method (1934 m), followed by WCT $(1923 \mathrm{~m})$, VAR $(1919 \mathrm{~m})$, and the GM methods (2177 m). The IPM/LGM methods overestimated that value since they found it to be at about $2400 \mathrm{~m}$, while the THR method estimation was at $866 \mathrm{~m}$. As a result of the low aerosol load inside the boundary layer, the maximum gradient is not always at the top of PBL and consequently the gradient-based methods are unable to correctly estimate it. On the other hand, the THR method also fails because of the turbulent fluxes inside the boundary layer.

\subsubsection{Case Study III: Sea Breeze}

The topography and the land cover characteristics of the Greater Athens area allows for local circulations such as sea (land)-breeze which are usually developed (Kallos et al. 1993) during the months of May-September (Melas et al. 1996). The onset of the sea-breeze at the coast occurs about 2.5 hours after sunrise, with the inland penetration observed as far as mountain Parnitha, about $30 \mathrm{~km}$ from the coastline reaching inland within around 3 hours after its development (Prezerakos, 1986). Sea (land)-breeze conditions results in a

sharp variation of the aerosol load in the lower atmosphere, something that usually complicates the determination of the PBL height by the lidar signal methods. A typical case (21 September 2012) with sea-breeze synoptic flow is shown in Fig. 5. The sunrise is at 0437 UTC while the solar noon at 0923 UTC. A steep increase of aerosol load inside the PBL is the result of the sea-breeze flow from land towards the sea and the development of an IBL, which is linked to unstable stratification (Batchvarova and Gryning 1998). When this air flow weakens after 1100 UTC, a sharp decrease of the aerosol concentration is observed inside the bound ary layer. 


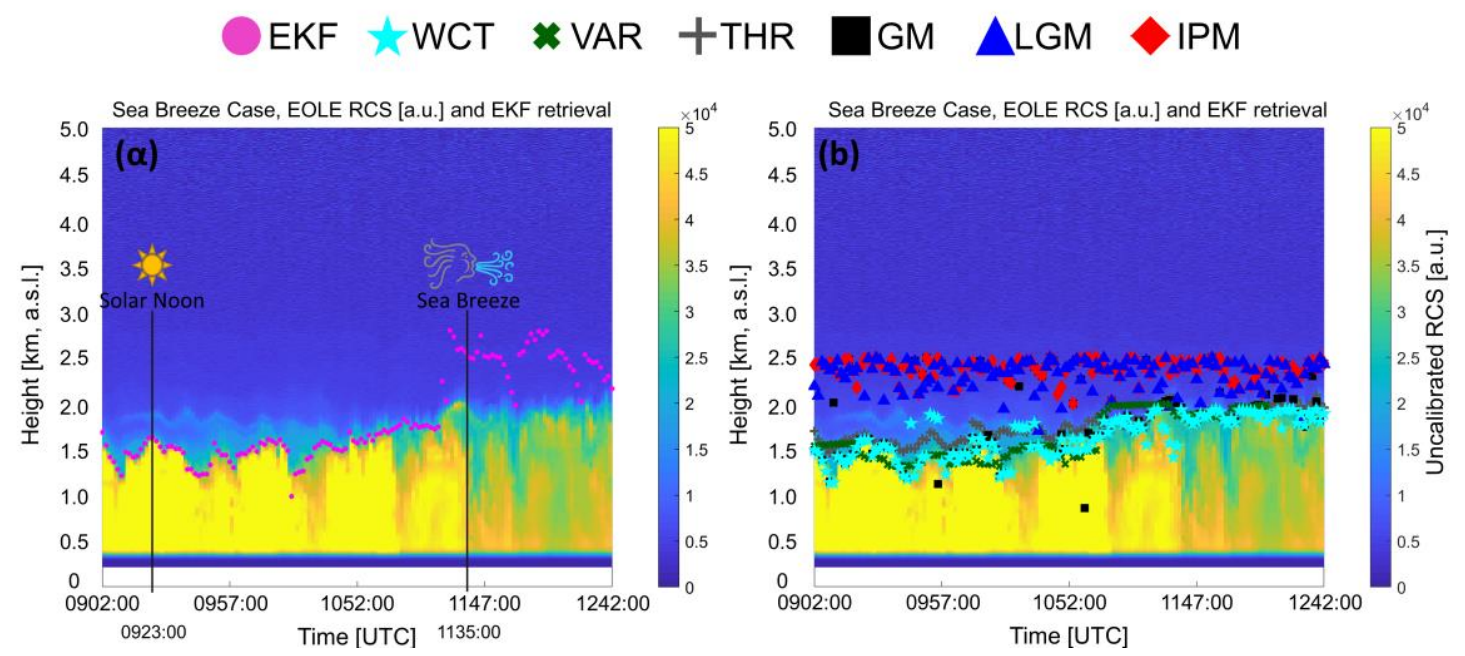

Fig. 5 Spatio-temporalevolution of EOLE RCS (in a.u.) and PBL height estimates during a case study of seabreeze conditions over Athens: (a) EKF estimates (pink dots), (b) Classical-methods estimates: WCT, turquoise stars; VAR, green $\mathrm{x}$; THR, grey crosses; GM, black squares; LGM, red rhombuses; IPM, blue triangles

The PBL height estimated by the radiosonde is $1912 \mathrm{~m}$ (1200 UTC). In this case, the closest to the radiosonde estimation is made by WCT method $(1916 \mathrm{~m})$, followed by the estimation made by the THR method (1905 m). The VAR/GM methods also succeed in a good estimation with their retrievals (about $1813 \mathrm{~m}$ ). The EKF/LGM/IPM methods, failed to detect the PBL height accurately, resulting in values of $2312 \mathrm{~m}, 2467 \mathrm{~m}$ and $2395 \mathrm{~m}$ a.s.l., respectively. The failure of the EKF method can be attributed to its basic principle, which takes into account the information retrieved from the past time frame in order to form the statistical indicators used for the estimation of the unknown PBL height in the near future time frame. Under such conditions, it is necessary to proceed with a reinitialization of EKF method just after the steep change of the aerosol load in order to achieve better results.

\subsubsection{Case Study IV: Clear Sky}

In this case, we consider that clear sky conditions refer to a day that (a) is cloudless and (b) the aerosol load in the free troposphere is negligible (less than $10 \%$ compared to the 
atmospheric column). A representative case study (22 September 2012) is shown in

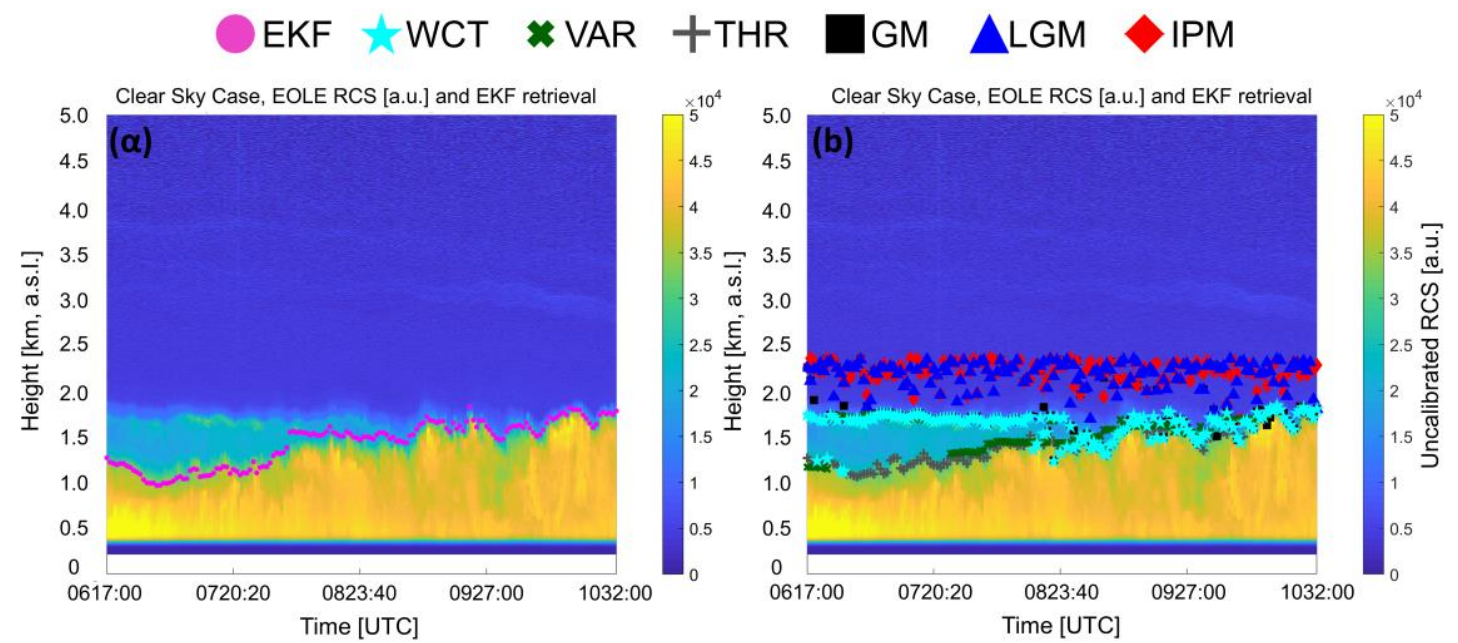

Fig. 6, according to which the PBL is well mixed vertically and grows at a rate of $110 \mathrm{~m} \mathrm{~h}^{-}$ ${ }^{1}$ (from $1325 \mathrm{~m}$ at 0617 UTC to $1767 \mathrm{~m}$ at $1005 \mathrm{UTC}$ ). The residual layer from the previous night is still evident above the PBL at $1600 \mathrm{~m}$ until 0800 UTC.

The PBL height estimated by the radiosonde is found to be $1712 \mathrm{~m}$ at $1000 \mathrm{UTC}$. The closest retrieval to this value is provided by the EKF method $(1650 \mathrm{~m})$, while the THR/WCT methods are following with $1640 \mathrm{~m}$ and $1620 \mathrm{~m}$, respectively. The VAR/GM methods also succeed in providing a PBL height (about $1600 \mathrm{~m}$ ) very close to our reference.

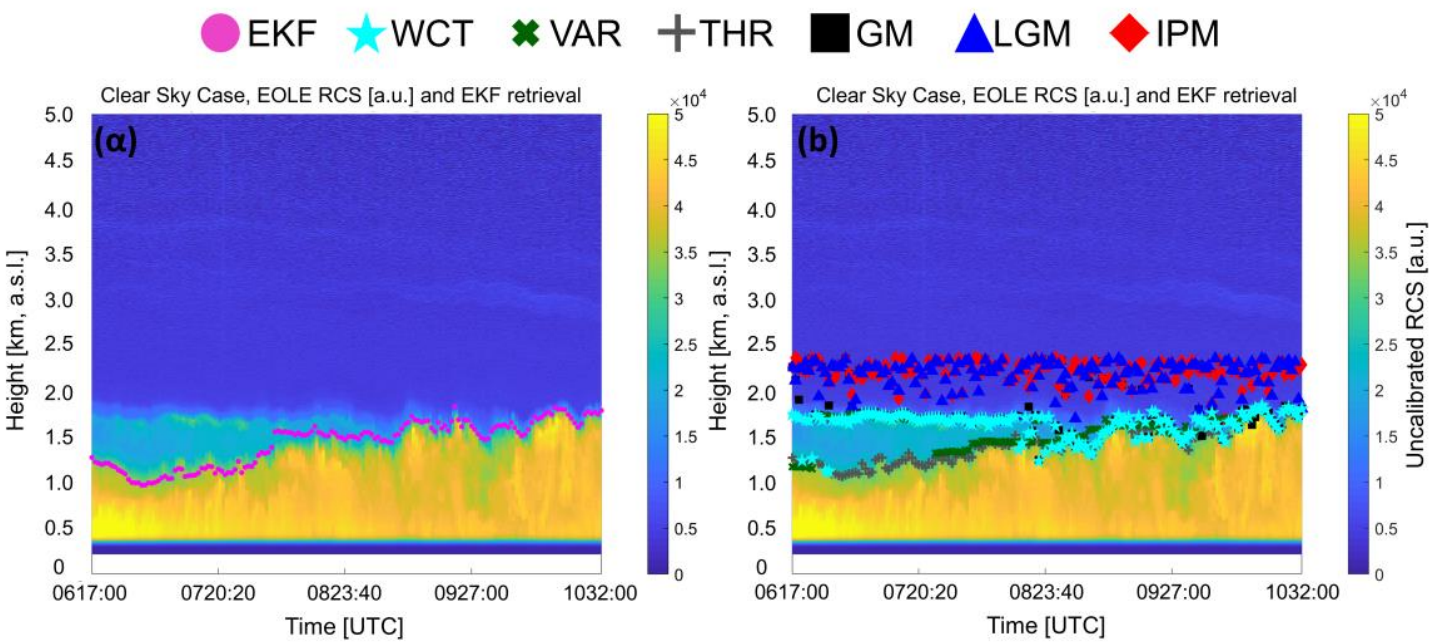

Fig. 6 Spatio-temporal evolution of EOLE RCS (in a.u.) and PBL height estimates during clear conditions over Athens: (a) EKF estimates (pink dots), (b) Classical-methods estimates: WCT, turquoise stars; VAR, green $\mathrm{x}$; THR, grey crosses; GM, black squares; LGM, red rhombuses; IPM, blue triangles 
On the other hand, the LGM/IPM methods overestimate the PBL height with values reaching $2250 \mathrm{~m}$. The EKF/THR methods are not affected by the presence of the residual layer and manage to determine accurately the PBL evolution. The THR method benefits from the well-mixed state of the boundary layer, which also demonstrates higher aerosol concentration compared to the residual layer.

\subsubsection{Case Study V: Cloud Case}

The presence of clouds at the PBL top introduces various difficulties towards estimating the PBL height. A representative case (01 June 2014) is shown in Fig. 7, where low-altitude scattered clouds are developed at around 0800 UTC, 1000 UTC, and 1300 UTC. Their presence is obvious by the strong backscattered RCS (values above $5 \times 10^{4}$ a.u.).

The radiosonde-estimated PBL height is $1568 \mathrm{~m}$ at 0800 UTC. Apart from the THR method, which determines it at $1188 \mathrm{~m}$, the rest of the lidar-based methods provide similar estimations to the sounding reference $(1750 \mathrm{~m})$. Generally, the presence of clouds results in a maximum gradient to the RCS that prevents the accurate determination of the PBL height. Therefore, it is obvious that gradient-based and VAR methods will detect the top of the PBL at the height of the cloud. Moreover, it is well known that WCT method fails to estimate accurately the PBL height if clouds are formed within the PBL (Baars et al. 2008).

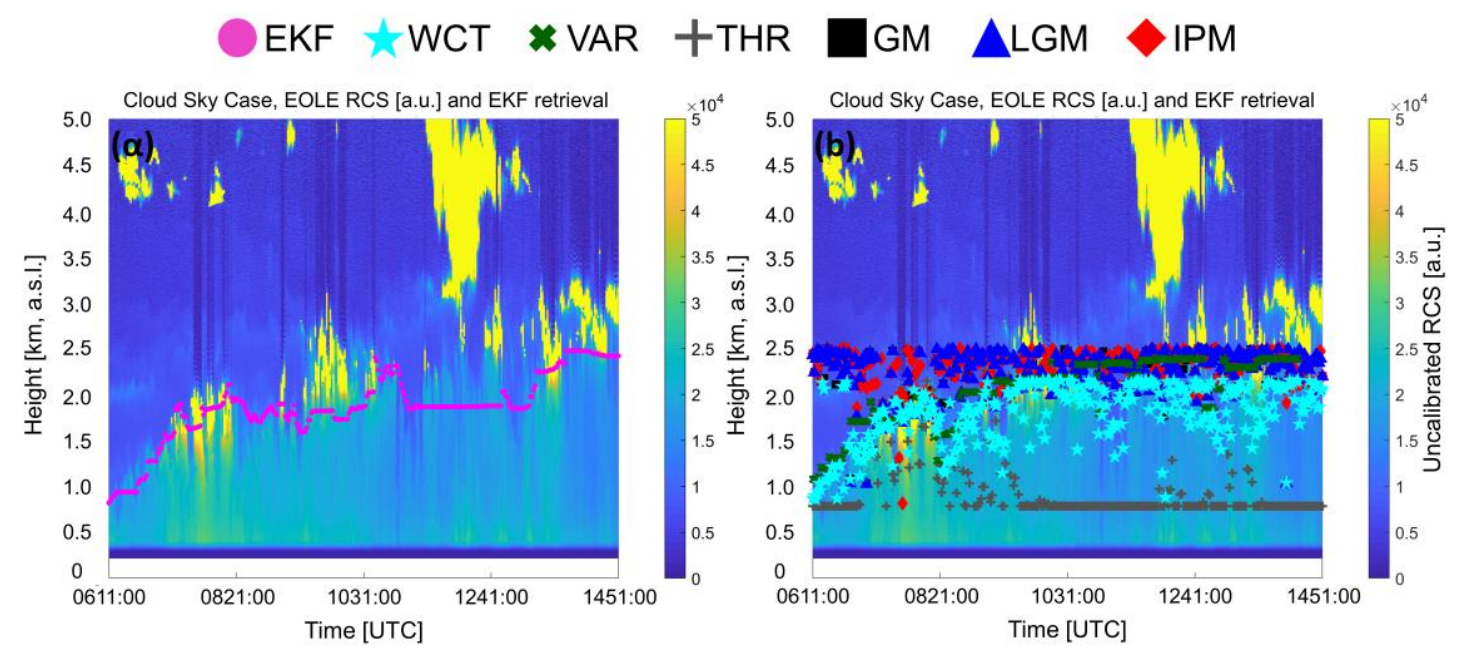

Fig. 7 Spatio-temporal evolution of EOLE RCS (in a.u.) and PBL height estimates during scattered cloud conditions over Athens: (a) EKF estimates (pink dots), (b) Classical-methods estimates: WCT, turquoise stars; VAR, green x; THR, grey crosses; GM, black squares; LGM, red rhombuses; IPM, blue triangles 
Indeed, Fig. 7 shows that WCT method is adversely affected by the presence of clouds inside the PBL, both at 1241 UTC and at 1400 UTC. Additionally, the THR method is useless in this case, as the presence of cloud results in a lower PBL height estimation. The EKF method performed moderately in these cases because past estimates are used to mitigate misestimating the actual PBL height.

\subsubsection{Case Study VI: Nocturnal Boundary Layer}

The nocturnal boundary layer height is often characterized by a stable layer, which forms when the radiative cooling and the surface friction stabilize the lowest part of the atmospheric layer. Despite that, the nocturnal stable boundary layer is often too low to be captured by lidar, which can only be achieved in low latitude regions and especially during summer months (Di Girolamo et al. 1999; Kolev et al. 2000).

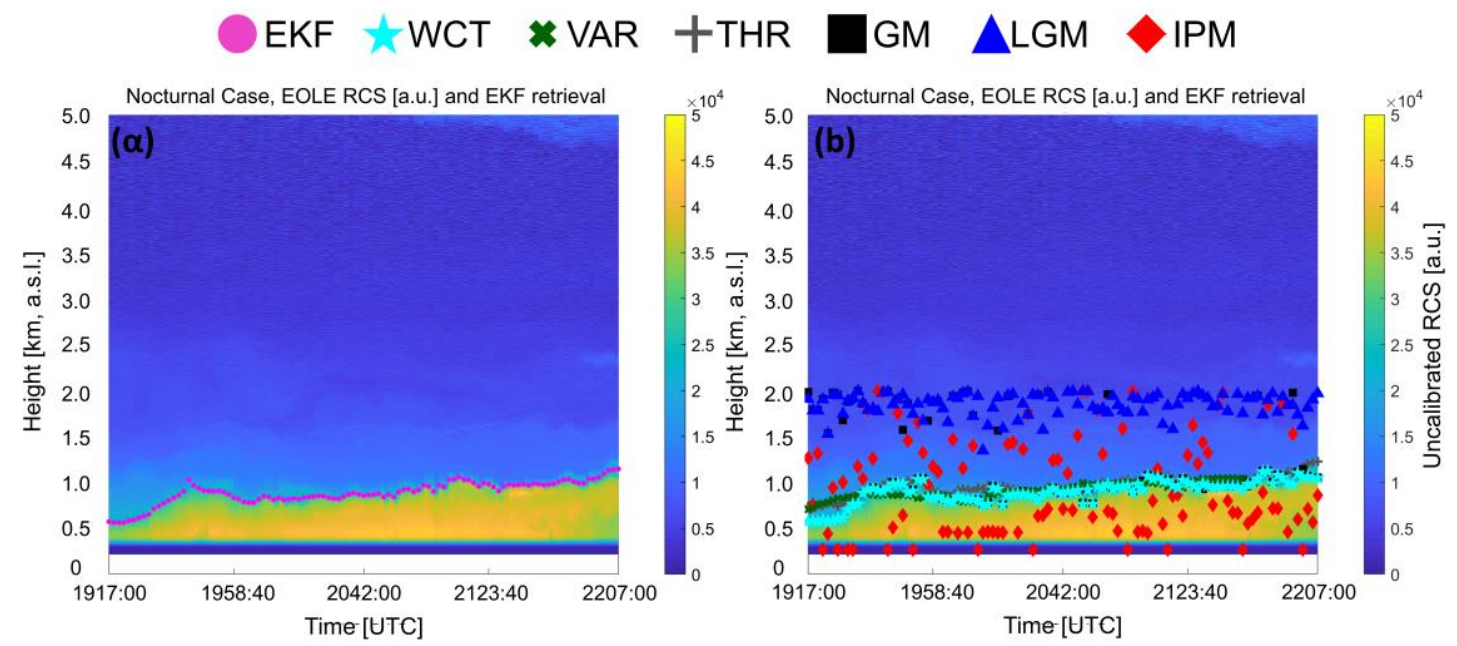

Fig. 8 Spatio-temporalevolution of EOLE RCS (in a.u.) and PBL height estimates during a ca se of nocturnal boundary layer over Athens: (a) EKF estimates (pink dots), (b) Classical-methods estimates: WCT, turquoise stars; VAR, green x; THR, grey crosses; GM, black squares; LGM, red rhombuses; IPM, blue triangles

In Fig. 8, we present a typical case of a nocturnal boundary layer (14 July 2011) that slowly rises from $600 \mathrm{~m}$ at 1917 UTC to $1052 \mathrm{~m}$ at 2207 UTC. A weak residual layer on top of that layer is also observed at $1500 \mathrm{~m}$. The boundary layer height, estimated by the radiosounding at $2200 \mathrm{UTC}$, is $1033 \mathrm{~m}$. The EKF/WCT/THR/VAR/GM methods succeed in producing good estimations at around $1000 \mathrm{~m}$, while the IPM/LGM revealed values of $1504 \mathrm{~m}$ and $789 \mathrm{~m}$, respectively. The weak aerosol load inside the nocturnal boundary layer 
in combination with the stability of the layer enables the lidar-based methods to make good estimation of the PBL height.

\subsubsection{Case Study VII: Nocturnal Boundary Layer with Residual Layer}

A quite frequent case at night-time is the presence of the residual layer on top of the nocturnal boundary layer (Fig. 9, 11 July 2011). Gradient method s usually detect one layer, resulting in misidentification of the nocturnal PBL, since they are insensitive to this inner stratification. The residual layer is usually detected instead, which makes gradient methods useless.

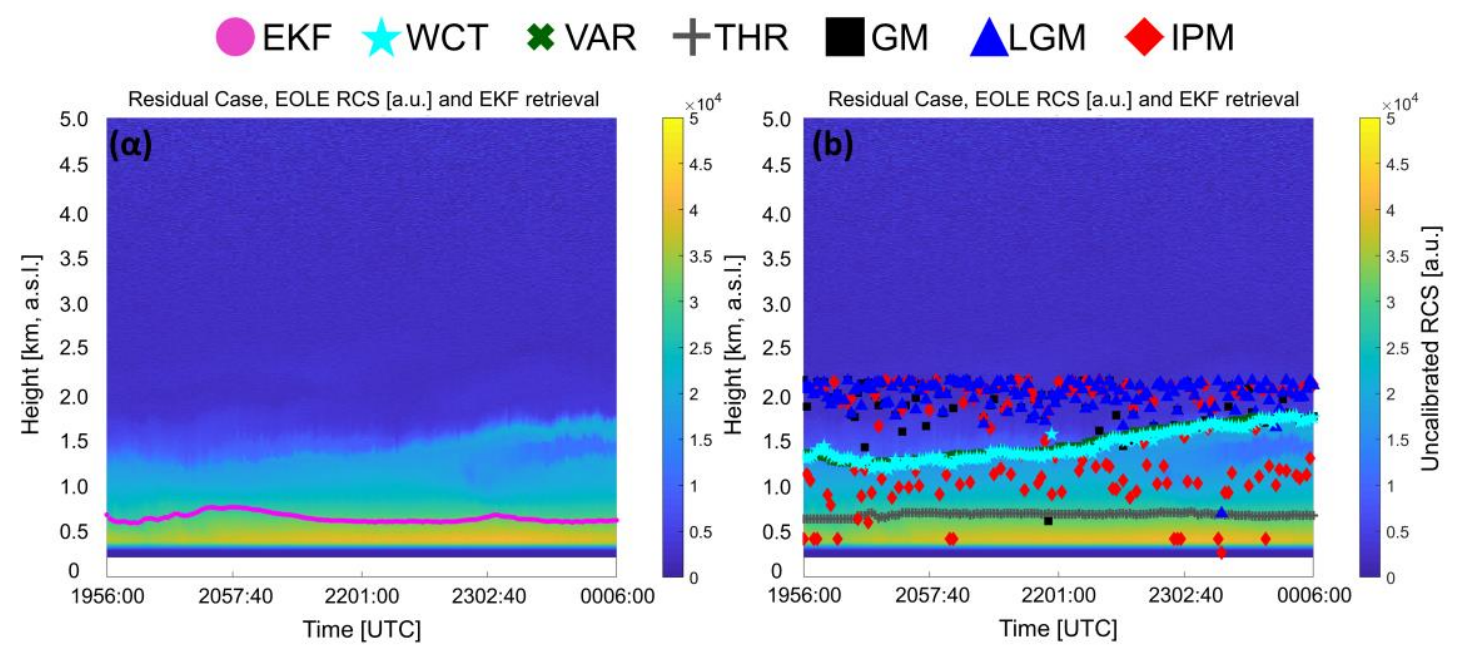

Fig. 9 Spatio-temporalevolution of EOLE RCS (in a.u.) and PBL height estimates during a case of residual boundary layer over Athens: (a) EKF estimates (pink dots), (b) Classical-methods estimates: WCT, turquoise stars; VAR, green x; THR, grey crosses; GM, black squares; LGM, red rhombuses; IPM, blue triangles

The nocturnal boundary layer estimated by the weather balloon is at $618 \mathrm{~m}$. It is evidenced that the only methods that make correct estimation of nocturnal bound ary layer are the EKF/THR methods (around $520 \mathrm{~m}$ and $650 \mathrm{~m}$, respectively). On the other hand, the WCT/VAR/LGM/GM methods incorrectly determine the residual layer as the boundary layer (around $1700 \mathrm{~m}$ ), while IPM technique makes the worst estimation (around $1998 \mathrm{~m}$ ).

\subsection{Comparative Results}

In Fig. 10 we present scatter plots of the mean PBL height derived from the different methods in comparison to radiosonde retrievals, and for the different atmospheric 
conditions presented (coloured solid circles), along with the corresponding statistical correlation coefficient $\left(R^{2}\right)$. For the determination of $R^{2}$ values we used the RCS obtained at the launching time of the radiosonde (around 1200 UTC). It is obvious that the PBL height derived from the EKF method gives the best correlation compared to the one derived from the radiosonde data $\left(R^{2}=0.89\right)$, while the WCT method exhibits the second strongest correlation coefficient $\left(R^{2}=0.75\right)$, followed by the THR method with $R^{2}=$ 0.63. Weaker correlations are observed for the VAR and the gradient-based methods. On the other hand, since the radiosounding site and the lidar facility are not co-located but within 12-km distance, we also had to take into account any possible spatial inhomogeneity that may exist over the urban environment of Athens. Thus, we once again compared our data, but this time by temporally averaging the retrieved PBL height within a window of \pm $30 \mathrm{~min}$ from the launch time of the radiosonde. We refer to these correlation coefficients as $R_{\text {mean }}^{2}$. The relative change between the two coefficients is a good criterion in order to make clear which method best describes PBL height and, therefore its suitability for PBL growth-rate investigations.

As shown in Fig. 10, the EKF/WCT, and threshold methods seem to have stable performances, demonstrating only $5.4 \%, 11.7 \%$, and $16 \%$ relative change, the highest change found for the logarithmic gradient method (66.6\%), while for the rest methods the $R^{2}$ changed up to $45 \%$. The EKF method keeps on having the highest correlation coefficient, and since it has not been significantly improved (from $R^{2}=0.89$ to $R^{2}=$ 0.94) this indicates that the EKF best describes PBL height variability. On average, only 
the THR method is found to underestimate the PBL top by $299 \mathrm{~m}$ as compared to all other methods while gradient-based methods overestimate it by around $400 \mathrm{~m}$.
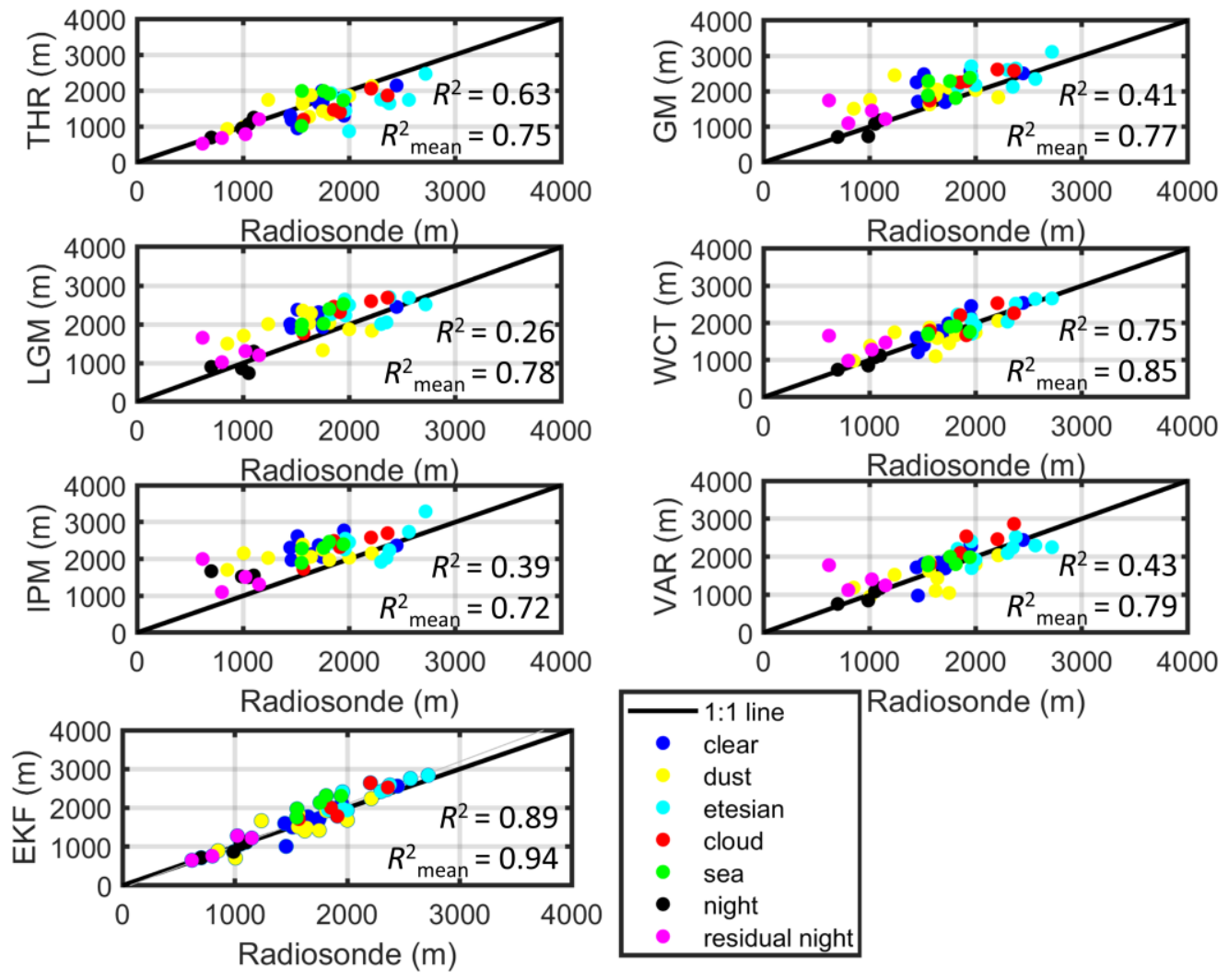

Fig. 10 Scatter plots of PBL height retrieved from lidar-based methods and radiosondes, under various atmospheric conditions

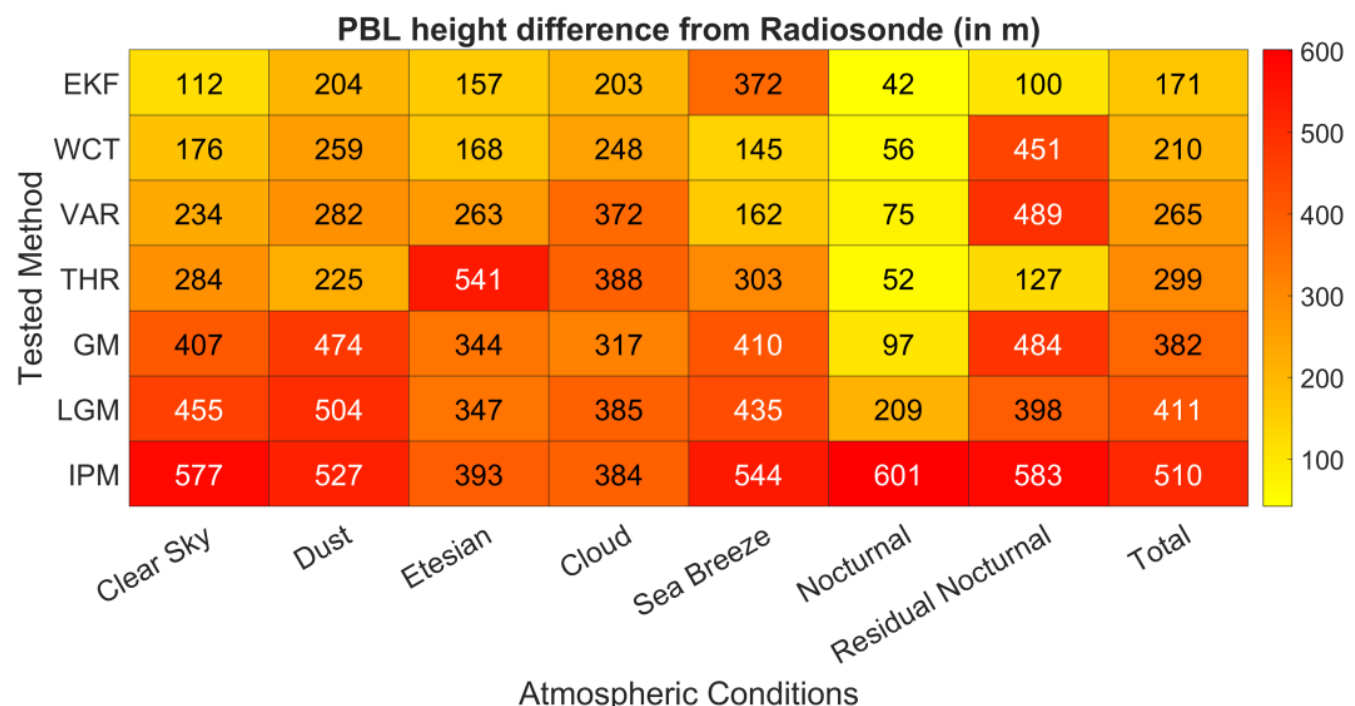

Fig. 11 Heatmap of the mean absolute difference between the PBL height retrieved using lidar-based methods and the one estimated using radiosondes, for various atmospheric conditions 
In

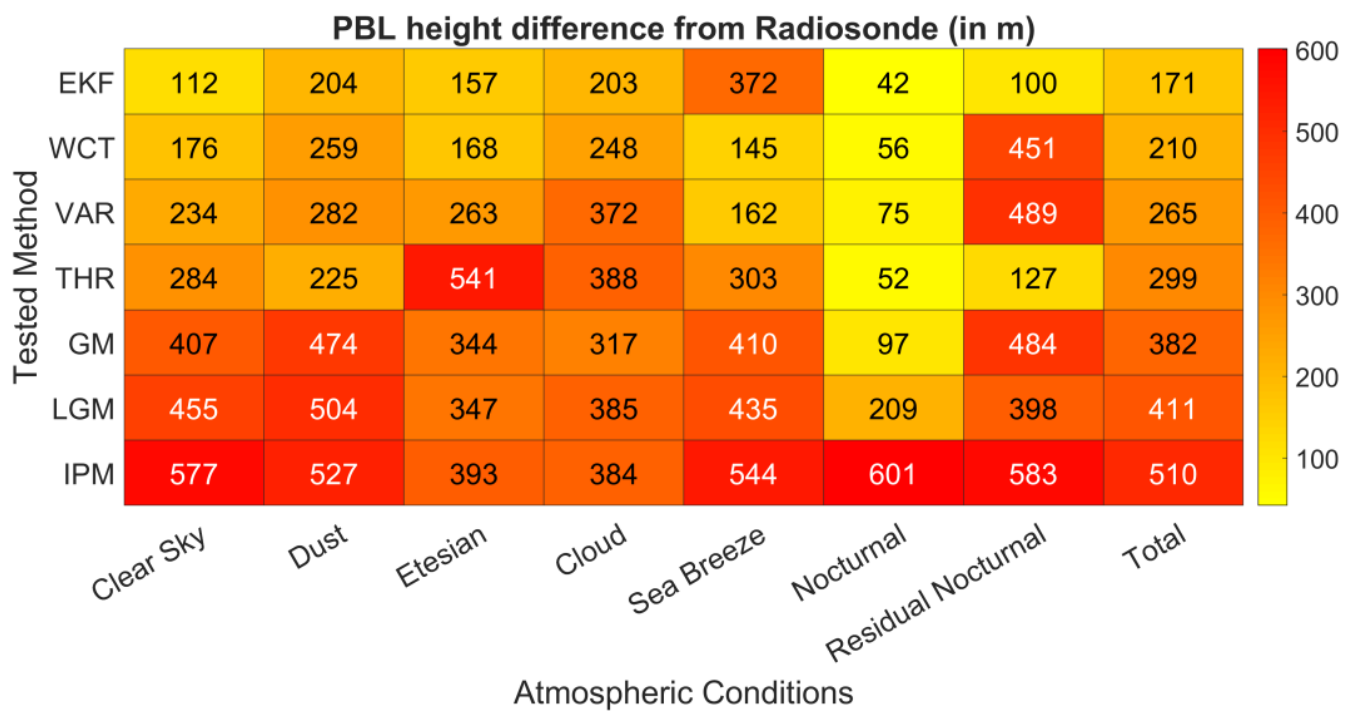

Fig. 11 we present the mean absolute difference between the PBL height estimations, retrieved from lidar and radiosonde data under various atmospheric conditions and for the entire sample dataset. The EKF method presents the minimum difference with the radiosonde $(171 \mathrm{~m})$ followed by the WCT/VAR methods, with $210 \mathrm{~m}$ and $265 \mathrm{~m}$ difference, respectively. The THR method works moderately well with a mean difference of $299 \mathrm{~m}$, while the GM/LGM/IPM methods present the higher differences around $382 \mathrm{~m}$, $411 \mathrm{~m}$, and $510 \mathrm{~m}$, respectively.

\subsection{Monthly Variability}

In this section we present statistical values related to the monthly variability of the PBL height, as retrieved from EOLE measurements, obtained during the time period January 2011-October 2016. Our dataset is comprised by almost an equal amount of observations for days and nights, 167 and 165 cases respectively. The monthly distribution of these measurements during day and night is almost the same. However, the amount of observations for each month varies significantly. For example, during August, there are a few daily cases (less than 5), and thus our statistical analysis cannot be considered as representative for this month. Instead, our measurement availability during June is high (more than 10), for both day and night conditions. 
In Fig. 12 we present the monthly variability of the PBL height during daytime (observation at 1200 UTC) and night-time (0000 UTC) for the entire time period of measurements, as estimated by applying the EKF technique to the EOLE lidar signals. During daytime, the mean PBL height value is found to be $R_{b l}=1617 \pm 324 \mathrm{~m}$, varying from 982 m (December) up to 2090 m (July). Matthias et al. (2004), found the mean PBL height over Athens (for 81 cases) to be equal to $1179 \pm 319 \mathrm{~m}$. Moreover, in this work we notice a strong variability of PBL height with higher values during the summer months and lower values during the winter months. The main reason behind this is the larger statistical sample that we have during spring-summer months compared to the rest. Also, especially during the summer, the etesian winds are common along the Aegean Sea in Greece, as well as the long-range advection of transboundary dust load, affecting the dynamics of the boundary layer and resulting in a high variability of the PBL height. During night-time, the PBL height was found to be stable, with a mean value of $892 \pm 130 \mathrm{~m}$.

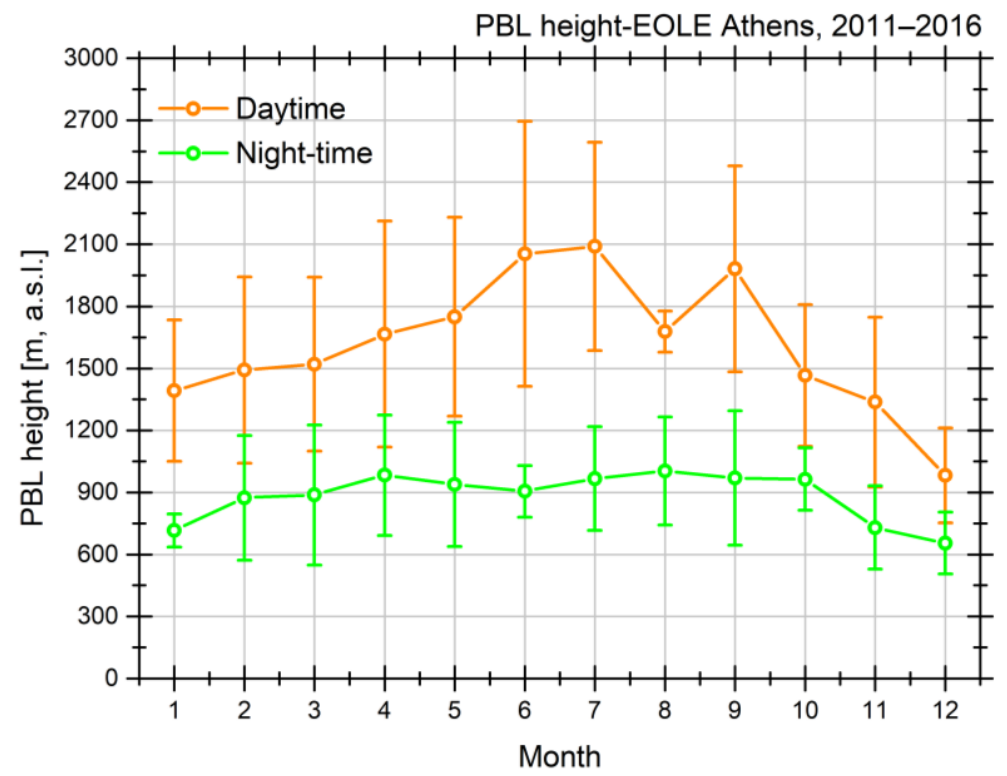

Fig. 12 Monthly variability (2011-2016) of PBL height, daytime and night-time, as estimated by the EKF technique 


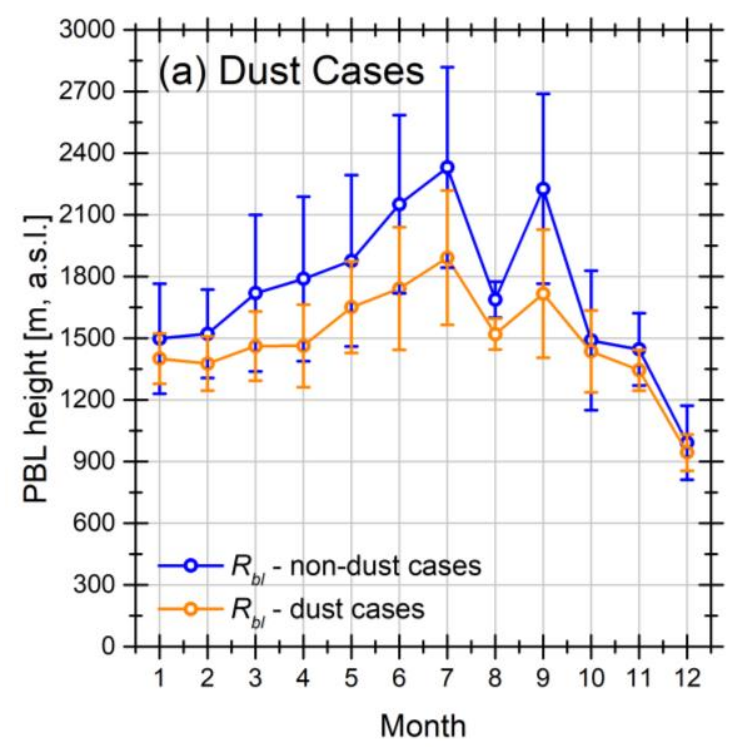

PBL height - EOLE Athens, 2011-2016

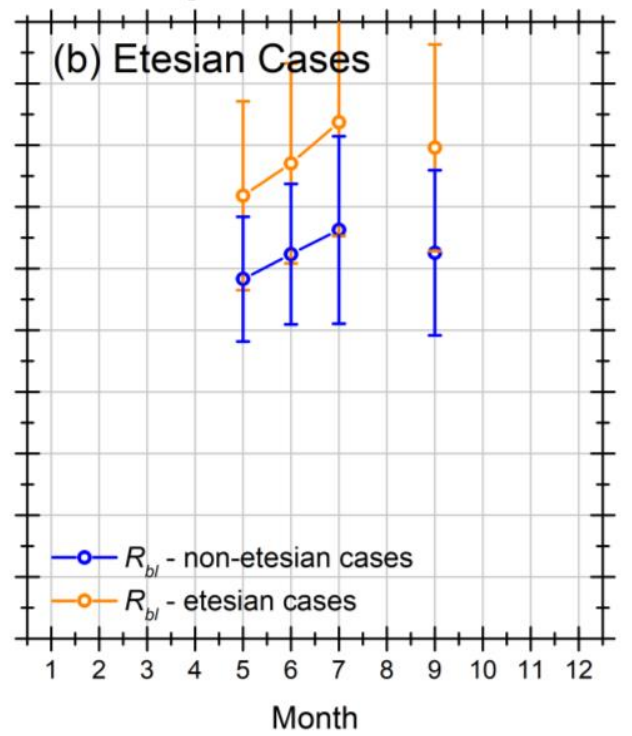

Fig. 13 Monthly variability (2011-2016) of PBL height as estimated by the EKF technique. (a) Dust and non-dust cases, (b) etesian and non-etesian cases

The effect of the dust load in the monthly mean PBL height is shown in Fig. 13a. A dust layer located above the boundary-layer top is leading to significantly lower height values as compared to the corresponding values observed during non-dust days. The monthly variability of the PBL height for the dust cases showed a strong dependence on season. More precisely, the mean PBL height was found to be about $259 \pm 67 \mathrm{~m}$ lower during cases of dust particles suspended in the atmosphere as compared to the rest days without dust load. Additionally, during the months that Greece is mostly affected by high Saharan dust loads (May-September without taking into account August due to the low number of observations) (Papayannis et al. 2008), the aforementioned difference in the PBL height reaches the $475 \pm 83 \mathrm{~m}$. In contrast, in those cases where etesian winds prevail over Athens (36 in total), which is typical of summer, the PBL height is found to be $407 \pm$ $39 \mathrm{~m}$ higher than the rest of the days.

Taking advantage of the EKF method, and its capability to provide continuous results from the lidar signal, we studied the growth of the PBL depth in the morning and early afternoon hours. In the following, we denote the increase of the PBL top height within one hour as the "hourly growth rate". Similarly, the mean daytime growth rate $\left(\frac{\Delta R_{b l}}{\Delta t}=\frac{R_{b l, 2}-R_{b l, 1}}{t_{2}-t_{1}}\right)$ describes the increase of the PBL top from the nocturnal value $\left(R_{b l, 1}\right)$, 
observed about 4 hours after sunrise $\left(t_{1}\right)$, to the maximum value $\left(R_{b l, 2}\right)$ (at about 1000 1200 UTC), or at the time at which the PBL top is at least $90 \%$ of the maximum height observed on this day $\left(t_{2}\right)$. The PBL growth at night-time refers to the growth of the nocturnal PBL (i.e., the mixed layer under the residual layer), estimated from lidar measurements performed from the sunset up to three to five hours onwards (e.g., 18002300 UTC).

The results of this study (based on the 135 days) are shown in Fig. 14 for the mean hourly growth rate in a monthly basis. Because of the strong annual cycle of incoming radiation, higher values of the PBL-height growth rate are observed in the summer period (May-September). The mean monthly value is found to be $\frac{\Delta R_{b l}}{\Delta t}=170 \pm 64 \mathrm{~m} \mathrm{~h}^{-1}$, with maximum observations occurring during July $\left(267 \pm 61 \mathrm{~m} \mathrm{~h}^{-1}\right)$, and minimum during December $\left(74 \pm 30 \mathrm{~m} \mathrm{~h}^{-1}\right)$.

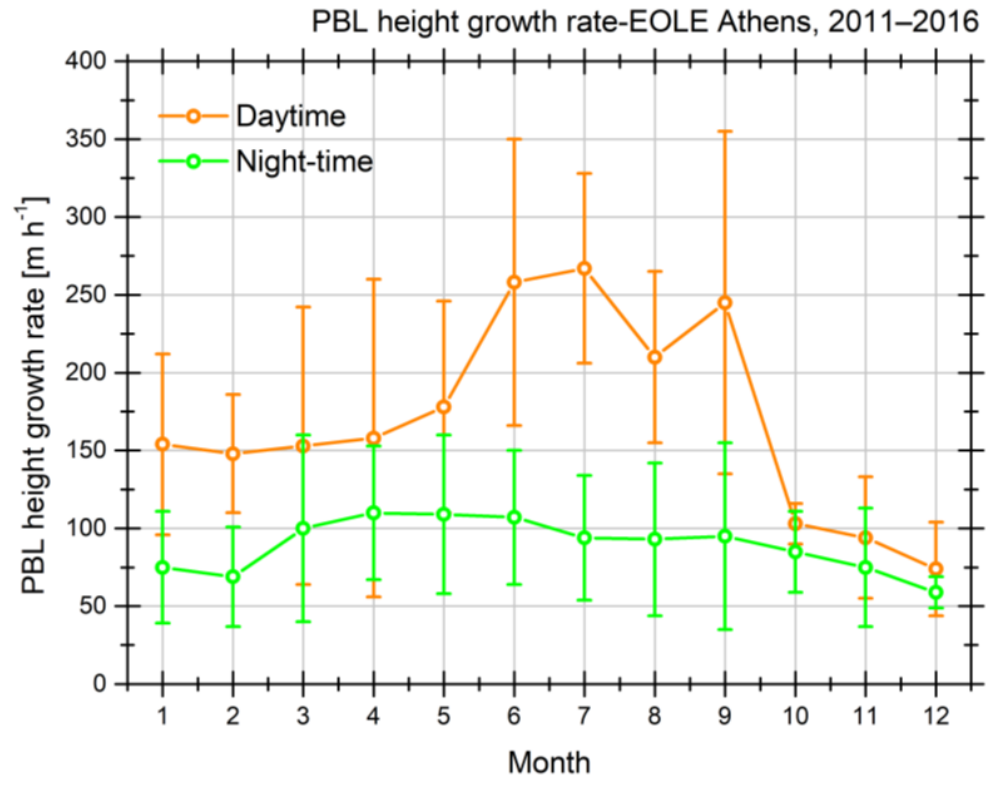

Fig. 14 Monthly variability (2011-2016) of the PBL-height growth rate (in $\mathrm{m} \mathrm{h}^{-1}$ ), daytime and night-time, as estimated by the EKF technique 

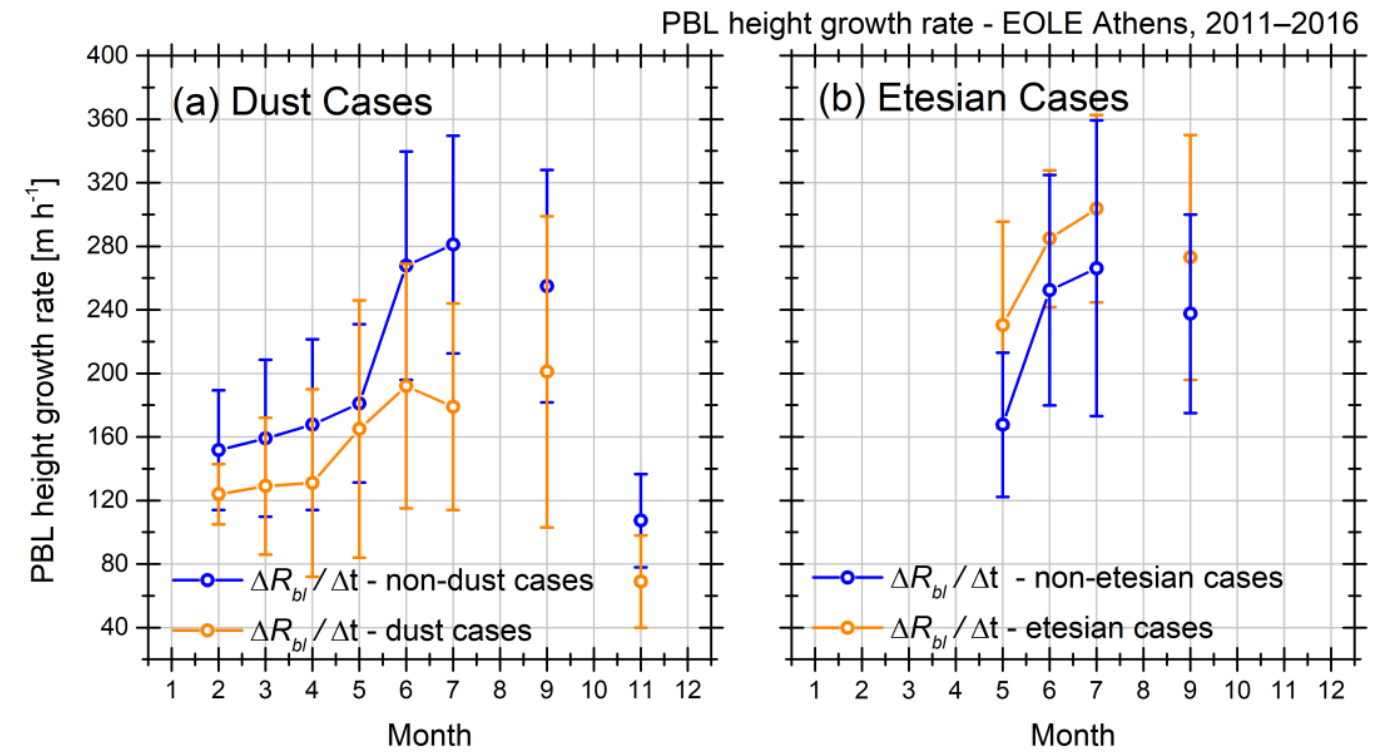

Fig. 15 Monthly variability (2011-2016) of the PBL-height growth rate (in $\mathrm{m} \mathrm{h}^{-1}$ ) as estimated by the EKF technique. (a) Dust and non-dust cases, (b) etesian and non-etesian cases

The effect of specific atmospheric condition on the PBL-height growth rate is shown in Fig. 15. During dust events, it seems that not only does the PBL becomes sallow, but it also takes more time to be developed, since the mean monthly growth rate is found to be $\frac{\Delta R_{b l}}{\Delta t}=149 \pm 44 \mathrm{~m} \mathrm{~h}^{-1}$, almost $20 \%$ lower than the mean annual growth rate. This can be attributed to the presence of the dust layer itself, which reduces the amount of incoming shortwave radiation to Earth surface. In contrast, for the etesian cases the development of the PBL seems to occur faster, with a mean monthly value of $273 \pm 31 \mathrm{~m} \mathrm{~h}^{-1}$ (around $43 \mathrm{~m}$ $\mathrm{h}^{-1}$ faster than the corresponding value of the rest days). A possible explanation for this may be the enhancement of turbulent flows due to the high wind speed characteristic of etesian winds over Athens. Under such conditions the increased turbulence kinetic energy may expand the bound ary layer quickly.

\section{Conclusions}

PBL heights estimated by the EKF technique and other common lidar-based methods were compared to radiosonde retrievals. The comparison was performed on a case study level but also on a 6-year time period statistical basis (2011-2016) under various atmospheric conditions and aerosol loads. 
The EKF method showed to be the most efficient estimator under the most usual meteorological conditions, finding the PBL height with a mean difference of $171 \mathrm{~m}$ from the corresponding radiosonde retrievals. However, the EKF method found difficult to track the PBL under sea-breeze conditions, which usually cause a steep change in the aerosol load inside the PBL. A solution to this would be to re-initialize the EKF after such steep change of aerosol load. The WCT method was second in the ranking, estimating the PBL height with $210 \mathrm{~m}$ discrepancy. Its weak point was tracking the nocturnal boundary layer because the residual layer was misclassified as the nocturnal layer. The VAR and WCT methods showed similar performance. Although the THR method was more accurate in the determination of the nocturnal boundary layer (mean difference of $127 \mathrm{~m}$ ), and worked moderately well in many other conditions, the cases of etesian winds and clouds yield ed the largest errors, resulting to mean PBL height underestimations of $540 \mathrm{~m}$ and $388 \mathrm{~m}$, respectively. The gradient-based methods generally overestimated the PBL height within $382-510 \mathrm{~m}$.

In this study it has, also, been shown that the EKF method follows the temporal evolution of the PBL height much better than any other technique. Thus, when compared to the PBL height derived from radiosonde data, the EKF showed the highest correlation $\left(R^{2}=0.89\right.$ at $1200 \mathrm{UTC}$ and $R^{2}=0.94$ for $\left.1200 \mathrm{UTC} \pm 30 \mathrm{~min}\right)$.

For the studied time period and by applying the EKF technique, a mean PBL height of $1617 \pm 324 \mathrm{~m}(1200 \mathrm{UTC})$ and $892 \pm 130 \mathrm{~m}$ (0000 UTC) was found over Athens. The growth rate was found to be $170 \pm 64 \mathrm{~m} \mathrm{~h}^{-1}$ and $90 \pm 17 \mathrm{~m} \mathrm{~h}^{-1}$ daytime and night-time, respectively. Furthermore, the mean PBL height in dust cases was $259 \pm 67 \mathrm{~m}$ lower than in no-dust cases, and in etesian-wind cases, the retrieved height was $403 \pm 39 \mathrm{~m}$ higher than in non-etesian cases.

The significance of this work lies in revealing the strengths and limitations of the EKF technique, showing that is capable of providing accurate PBL height retrievals, on operational basis, under various atmospheric conditions.

Acknowledgements The research leading to these results has received additionalfunding from the European Union $7^{\text {th }}$ Framework Program (FP7/2011-2015) and Horizon 2020/2015-2021 Research and Innovation program (ACTRIS) under grant agreements nos 262254, 654109, and 739530, as well as from Spanish NationalScience Foundation and FEDER funds PGC2018-094132-B-I00. 
CommSensLab-UPC is a María-de-Maeztu Excellence Unit, MDM-2016-0600, funded by the Agencia Estatalde Investigación, Spain.

\section{References}

Amodeo A, D’Amico G, Giunta A, Papagiannopoulos N, Papayannis A, Argyrouli A, Mylonaki M, Tsaknakis G, Kokkalis P, Soupiona R, Tzanis C (2018) ATHLI16: the ATHens lidar intercomparison campaign. $28^{\text {th }}$ Interna tional La ser Radar Conference, 25-30 June 2017, Bucha rest, Romania, 176:09008.doi: 10.1051/epjconf/201817609008

Baars H, Ansmann A, Engelmann R, Althausen D (2008) Continuous monitoring of the boundary -layer top with lidar. Atmos Chem Phys 8:7281-7296. doi: 10.5194/acp-8-7281-2008

Banks RF, Tiana-Alsina J, Baldasano JM, Rocadenbosch F, Papayannis A, Solomos S, Tzanis CG (2016) Sensitivity of boundary-layer variables to PBL schemes in the WRF model based on surface meteorological observations, lidar, and radiosondes during the HygrA-CD campaign. Atmos Res 176-177:185-201.doi: 10.1016/j.atmosres.2016.02.024

Batchvarova E, Gryning SE (1998) Wind climatology, atmospheric turbulence and internal boundary -layer development in Athens during the MEDCAPHOT-TRACE experiment. Atmos Environ 32:20552069. doi: 10.1016/S1352-2310(97)00422-6

Boers R, W. Eloranta E (1986) Lidar measurements of the atmospheric entrainment zone and potential temperature jump across the top of the mixed layer. Boundary-Layer Meteorol 34:. doi: 10.1007/BF00120988

Brooks IM (2003) Finding Boundary Layer Top: Application of a wavelet covariance transform to lidar backscatter profiles. J Atmos Oceanic Technol 20:1092-1105. doi: 10.1175/15200426(2003)020<1092:FBLTAO>2.0.CO;2

Cohn SA, Angevine WM (2000) Boundary layer height and entrainment zone thickness mea sured by lidars and wind-profiling radars. J Appl Meteorol 39:1233-1247. doi: 10.1175/15200450(2000)039<1233:BLHAEZ>2.0.CO;2

Comerón A, Sicard M, Rocadenbosch F (2013) Wavelet correlation transform method and gra dient method to determine a erosol layering from lidar returns: Some comments. J Atmos Ocean Technol30:1189_ 1193. doi: 10.1175/JTECH-D-12-00233.1

Di Girolamo P, Ambrico PF, Amodeo A, Boselli A, Pappalardo G, Spinelli N (1999) Aerosol observations by lidar in the nocturnalboundary layer. Appl Opt 38:4585. doi: 10.1364/AO.38.004585

Dirksen RJ, Sommer M, Immler FJ, Hurst DF, Kivi R, Vömel H (2014) Reference quality upper-air mea surements: GRUAN data processing for the Vaisala RS92 radiosonde. Atmos Meas Tech 44634490. doi: doi: 10.5194/amt-7-4463-2014

Esau I, Zilitinkevich S (2010) On the role of the planetary boundary layer depth in the climate system. Adv Sci Res 4:63-69. doi: 10.5194/asr-4-63-2010

Escudero M (2005) Wet and dry African dust episodes over eastern Spain. J Geophys Res 110:. doi: 10.1029/2004JD004731

Fiedler S, Schepanski K, Knippertz P, Heinold B, Tegen I (2014) How important are atmospheric depressions and mobile cyclones for emitting mineral dust aerosol in North Africa? Atmos Chem Phys 14:89839000. doi: 10.5194/acp-14-8983-2014 
Flaounas E, Kotroni V, Lagouvardos K, Kazadzis S, Gkikas A, Hatzianastassiou N (2015) Cyclone contribution to dust transport over the Mediterranean region: Cyclone contribution to dust transport over the Mediterranean region. Atmos Sci Lett 16:473-478. doi: 10.1002/asl.584

Garratt JR (1994)The Atmospheric Boundary Layer. Cambridge University Press, Cambridge, UK

Garratt JR (1990) The internal boundary layer - A review. Boundary-Layer Meteorol 50:171-203. doi: $10.1007 / \mathrm{BF} 00120524$

Gerasopoulos E, Kokkalis P, Amiridis V, Amiridis V, Liakakou E, Perez C, Haustein K, Eleftheratos K, Andreae MO, Andreae TW, Zerefos CS (2009) Dust specific extinction cross-sections over the Eastern Mediterranean using the BSC-DREAM model and sun photometer data: the case of urban environments. Ann Geophys 27:2903-2912. doi: 10.5194/angeo-27-2903-2009

Hooper WP, Eloranta EW (1986) Lidar measurements of wind in the planetary boundary layer: The method, accuracy and results from joint mea surements with radiosonde and kytoon. J Climate Appl Meteor 25:990-1001. doi: 10.1175/1520-0450(1986)025<0990:LMOWIT>2.0.CO;2

Kallos G, Kassomenos P, Pielke RA (1993) Synoptic and mesosca le weather conditions during air pollution episodes in Athens, Greece. Boundary-Layer Meteorol62:163-184. doi: 10.1007/BF00705553

Kallos G, Papadopoulos A, Katsafados P, Nickovic S (2006) Transatlantic Saharan dust transport: Model simulation and results. J Geophys Res 111:. doi: 10.1029/2005JD006207

Kalman RE (1990) A new approach to linear filtering and prediction problems. J Basic Eng 82D:35-45. doi: $10.1115 / 1.3662552$

Kassomenos P, Kotroni V, Kallos G (1995) Analysis of climatological and air quality observations from Greater Athens Area. Atmos Environ 29:3671-3688. doi: 10.1016/1352-2310(94)00358-R

Kokkalis P (2017) Using paraxialapproximation to describe the optical setup of a typical EARLINET lidar system. Atmos Meas Tech 10:3103-3115. doi: 10.5194/amt-10-3103-2017

Kokkalis P, Papayannis A, Mamouri R-E, Tsaknakis G, Amiridis V (2012) The EOLE lidar system of the National Technical University of Athens. $26^{\text {th }}$ International Laser Radar Conference, 25-29 June 2012, Porto Heli, Greece, pp 629-632

Kolev I, Sa vov P, Kaprielov B, Parvanov O, Simeonov V (2000) Lidar observation of the nocturnal boundary layer formation over Sofia, Bulgaria. Atmos Environ 34:3223-3235. doi: 10.1016/S1352$2310(99) 00490-2$

Kotroni V, Lagouvardos K, Lalas D (2001) The effect of the island of Crete on the Etesian winds over the Aegean Sea. Q J R Meteorol Soc 127:1917-1937.doi: 10.1002/qj.49712757604

Labzovskii LD, Papayannis A, Binietoglou I, et al (2018) Relative humidity vertical profiling using lidarbased synergistic methods in the fra mework of the Hygra-CD ca mpaign. Ann Geophys 36:213-229. doi: 10.5194/angeo-36-213-2018

Lange D, Rocadenbosch F, Tiana-Alsina J, Frasier S (2015) Atmospheric boundary layer height estimation using a Kalman filter and a frequency-modulated continuous-wave Radar. IEEE Trans Geosci Remote 53:3338-3349. doi: 10.1109/TGRS.2014.2374233

Lange D, Tiana-Alsina J, Saeed U, Tomas S, Rocadenbosch F (2014) Atmospheric boundary layer height monitoring using a Kalman filter and backscatter lidar returns. IEEE Trans Geosci Remote 52:47174728. doi: 10.1109/TGRS.2013.2284110 
Melas D, Kambezidis HD (1992) The depth of the internal boundary layer over an urban area under sea breeze conditions. Boundary-La yer Meteorol 61:247-264. doi: 10.1007/BF02042934

Melas D, Ziomas I, Klemm O, Zerefos CS (1998) Anatomy of the sea-breeze circulation in Athens area under weak large-scale ambient winds. Atmos Environ 32:2223-2238. doi: 10.1016/S13522310(97)00420-2

Melfi SH, Spinhirne JD, Chou S-H, Palm SP (1985) Lidar observations of vertically organized convection in the planetary boundary layer over the ocean. J Climate Appl Meteor 24:806-821. doi: 10.1175/1520-0450(1985)024<0806:LOOVOC>2.0.CO;2

Menut L, Flamant C, Pelon J, Flamant PH (1999) Urban boundary-layer height determination from lidar measurements over the Paris area. Appl Opt 38:945.doi: 10.1364/AO.38.000945

Metaxas DA, Bartzokas A (1994) Pressure covariability over the Atlantic, Europe and N. Africa. application: Centers of action for temperature, winter precipitation and summer winds in Athens, Greece. Theor Appl Climatol 49:9-18.doi: 10.1007/BF00866284

Papayannis A, Amiridis V, Mona L, Tsaknakis G, Balis D, Bösenberg J, Chaikovski A, De Tomasi F, Grigorov I, Mattis I, Mitev V, Müller D, Nickovic S, Pérez C, Pietruczuk A, Pisani G, Ravetta F, Rizi V, Sicard M, Trickl T, Wiegner M, Gerding M, Mamouri RE, D'Amico G, Pappalardo G(2008) Systematic lidar observations of Saharan dust over Europe in the frame of EARLINET (2000-2002). Journal of Geophysical Research 113:. doi: 10.1029/2007JD009028

Papayannis A, Argyrouli A, Bougiatioti A, RemoundakiE, Vratolis S, Nenes A, Solomos S, Komppula M, GiannakakiE, Kalogiros J, Banks R, Eleftheriadis K, Mantas E, Diapouli E, Tzanis CG, Kazadzis S, Binietoglou I, Labzovskii L, Hey Vande J, Zerefos CS (2017) An overview from hygroscopic aerosols to cloud droplets: The HygrA-CD campaign in the Athens basin. Sci Tot Environ 574:216233. doi: 10.1016/j.scitotenv.2016.09.054

Pleim JE (2007) A combined local and nonlocal closure model for the atmospheric boundary layer. Part I: model description and testing. J Appl Meteor Climatol 46:1383-1395. doi: 10.1175/JAM2539.1

Poupkou A, Zanis P, Nastos P, Papanastasiou D, Melas D, Tourpali K, Zerefos C (2011) Present climate trend analysis of the Etesian winds in the Aegean Sea. Theor Appl Climatol 106:459-472. doi: 10.1007/s00704-011-0443-7

Prezerakos NG (1986) Characteristics of the sea breeze in Attica, Greece. Boundary-Layer Meteorol36:245266. doi: 10.1007/BF00118663

Richardson H, Basu S, Holtslag AAM (2013) Improving stable boundary-layer height estimation using a stability-dependent critical bulk Richardson number. Boundary-Layer Meteorol 148:93-109. doi: $10.1007 / \mathrm{s} 10546-013-9812-3$

Rocadenbosch F, Soriano C, Comerón A, Baldasano J-M (1999) Lidar inversion of atmospheric backscatter and extinction-to-backscatter ratios by use of a Kalman filter. Appl Opt, AO 38:3175-3189. doi: 10.1364/AO.38.003175

Rocadenbosch F, Vázquez G, Comerón A (1998) Adaptive filter solution for processing lidar retu rns: optical parameter estimation. Appl Opt, AO 37:7019-7034. doi: 10.1364/AO.37.007019

SchepanskiK, Knippertz P (2011) Soudano-Saharan depressions and their importance for precipitation and dust: a new perspective on a classical synoptic concept. Q J R Meteorol Soc 137:1431-1445. doi: 10.1002/qj.850 
Seibert P, Beyrich F, Gryning S-E, Joffre S, Rasmussen A, Tercier P (2000) Review and intercomparison of operational methods for the determination of the mixing height. Atmos Environ 34:1001-1027. doi: $10.1016 / \mathrm{S} 1352-2310(99) 00349-0$

Seidel DJ, Ao CO, Li K (2010) Estimating climatological planetary boundary layer heights from radiosonde observations: Comparison of methods and uncertainty analysis. J Geophys Res 115:. doi: 10.1029/2009JD013680

Sicard M, Pérez C, Rocadenbosch F, Baldasano JM, García-Vizcaino D (2006) Mixed-layer depth determination in the Barcelona coastalarea from regular lidar measurements: Methods, results and limitations. Boundary-Layer Meteorol 119:135-157. doi: 10.1007/s10546-005-9005-9

Sørensen JH, Rasmussen A, Svensmark H (1996) Forecast of atmospheric boundary -layer height utilised for ETEX real-time dispersion modelling. Phys Chem Earth 21:435-439. doi: 10.1016/S00791946(97)81138-X

Soupiona O, Papayannis A, Kokkalis P, Mylonaki M, Tsaknakis G, Argyrouli A, Vratolis S (2018) Longterm systematic profiling of dust a erosoloptical properties using the EOLE NTUA lidar system over Athens, Greece (2000-2016). Atmos Environ 183:165-174.doi: 10.1016/j.atmosenv.2018.04.011

Stull RB (1988) An Introduction to Boundary Layer Meteorology. Springer, Netherlands

Tombrou M, Bossioli E, Kalogiros J, Allan JD, Bacak A, Biskos G, Coe H, Dandou A, Kouvarakis G, Mihalopoulos N, Percival CJ, Protonotariou AP, Szabó-Takács B (2015) Physical and chemical processes of air masses in the Aegean Sea during Etesians: Aegean-GAME airborne campaign. Sci Tot Environ 506-507:201-216. doi: 10.1016/j.scitotenv.2014.10.098

Tsaknakis G, Papayannis A, Kokkalis P, Amiridis V, Kambezidis HD, Mamouri RE, Georgoussis G, Avdikos $\mathrm{G}$ (2011) Inter-comparison of lidar and ceilometer retrievals for aerosol and Planetary Boundary Layer profiling over Athens, Greece. Atmos Meas Tech 4:1261-1273. doi: 10.5194/amt-4-12612011

Tyrlis E, Škerlak B, Sprenger M, Wernli H, Zittis G, Lelieveld J (2014) On the linkage between the Asian summer monsoon and tropopause fold activity over the eastern Mediterranean and the Middle East. J Geophys Res Atmos 119:3202-3221. doi: 10.1002/2013JD021113

Vogelezang DHP, Holtslag AAM (1996) Evaluation and model impacts of alternative boundary-layer height formulations. Boundary-Layer Meteorol 81:245-269. doi: 10.1007/BF02430331

Vömel H, Selkirk H, Miloshevich L, Valverde-Canossa J, Valdés J, Kyrö E, Kivi R, Stolz W, Peng G, Diaz JA (2007) Radiation dry bia s of the Vaisala RS92 humidity sensor. J Atmos OceanTechnol 24:953963. doi: 10.1175/JTECH2019.1

Zecchetto S, De Biasio F (2007) Sea surface winds over the Mediterranean basin from satellite data (200004): Meso- and local-scale features on annual and seasonal time scales. J Appl Meteorol Climatol 46:814-827. doi: 10.1175/JAM2498.1

Zhang Y, Gao Z, Li D, Li Y, Zhang N, Zhao X, Chen J (2014) On the computation of planetary boundarylayer height using the bulk Richardson number method. Geosci Model Dev 7:2599-2611. doi: 10.5194/gmd-7-2599-2014

Zilitinkevich S, Baklanov A (2002) Calculation of the height of the stable boundary layer in practical applications. Boundary-Layer Meteorol 105:389-409. doi: 10.1023/A:1020376832738 